INVESTIGATING BUNDLED APPROACHES TO REDUCE GREENHOUSE GAS

EMISSIONS IN THE TORONTO 2030 DISTRICT

by

Patrick Ritsma

Honours Geography and Environmental Sciences (B.Sc.), McMaster University, 2015

\author{
A MRP \\ Presented to Ryerson University \\ in partial fulfillment of the \\ requirements for the degree of \\ Master of Building Science \\ In the Program of \\ Building Science
}

Toronto, Ontario, Canada, 2019

(C) Patrick Ritsma, 2019 


\section{AUTHOR'S DECLARATION FOR ELECTRONIC SUBMISSION OF A MRP}

I hereby declare that I am the sole author of this MRP. This is a true copy of the MRP, including any required final revisions, as accepted by my examiners.

I authorize Ryerson University to lend this MRP to other institutions or individuals for the purpose of scholarly research.

I further authorize Ryerson University to reproduce this MRP by photocopying or by other means, in total or in part, at the request of other institutions or individuals for the purpose of scholarly research.

I understand that my MRP may be made electronically available to the public. 


\title{
INVESTIGATING BUNDLED APPROACHES TO REDUCE GREENHOUSE GAS EMISSIONS IN THE TORONTO 2030 DISTRICT
}

\author{
Master of Building Science 2019, Patrick Ritsma
}

Building Science Program, Department of Architectural Science, Ryerson University

\begin{abstract}
Building energy models are an effective tool for evaluating energy reduction opportunities in both design phase and post-occupancy scenarios. By merging building energy models with city scale building stock data, it is possible to analyze energy performance at a greater breadth, providing more informed policy decisions and solutions to energy demand asymmetries in urban metropolises. This study examines the energy reduction potential for office buildings in the Toronto 2030 District, by testing individual and bundled energy conservation measures and greenhouse gas reduction strategies using a reference building energy model. When extrapolated across Toronto's urban core, simulation results determined that standard interventions on the existing office building stock have the potential to reduce greenhouse gas emissions by as much as $91.5 \%$, in line with 2030 District initiatives.
\end{abstract}




\section{ACKNOWLEDGMENTS}

I would like to thank my supervisor Jennifer McArthur, for her direction and insight in every part of my research, and for her inspiration as both an individual and an educator. I would like to thank my second reader, Russell Richman, for giving direction on this project, and providing guidance during my time in the Building Science program. I would like to thank Hannah Wegner and Richard Raustad for providing valuable data that was crucial to my results. I would also like to express gratitude to my parents, Ben and Jenny, as well as my girlfriend, Kat, for their continual support throughout my academic endeavours. 


\section{TABLE OF CONTENTS}

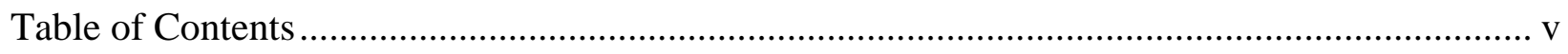

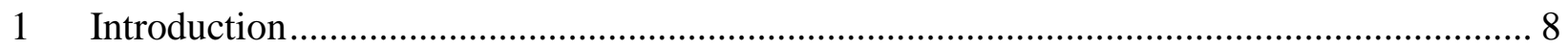

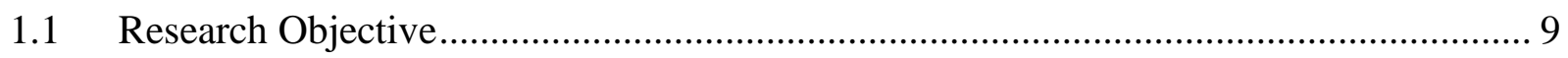

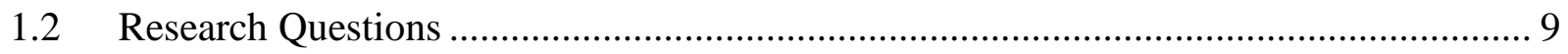

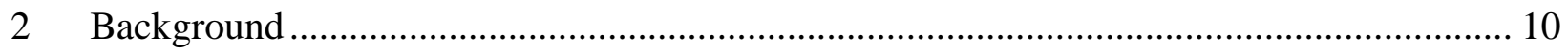

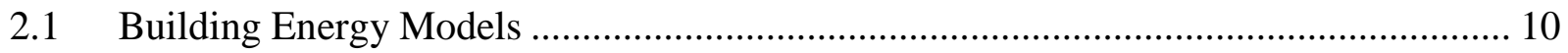

2.2 Energy Conservation and Greenhouse Gas Reduction Strategies................................. 11

2.3 Urban Building Energy Models ............................................................................ 12

2.4 Public Web Based Urban Energy Models ................................................................. 13

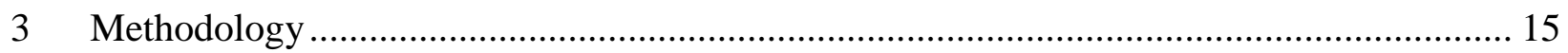

3.1 Data Collection and Typology Selection …………................................................ 17

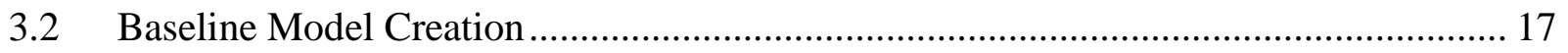

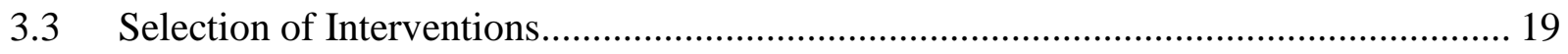

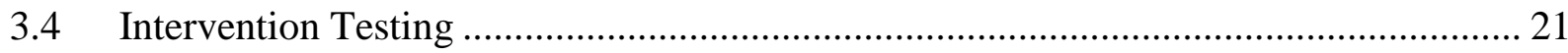

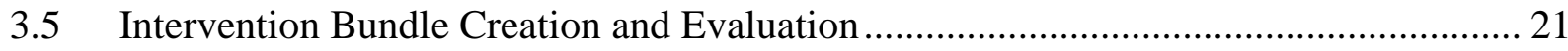

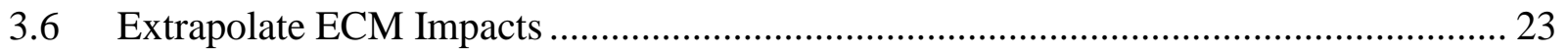

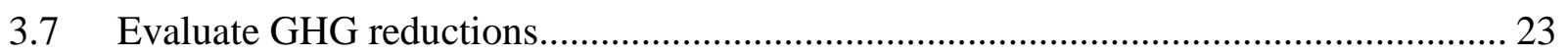

3.8 Determine Intervention Scenarios and Recommend Course of Action ......................... 23

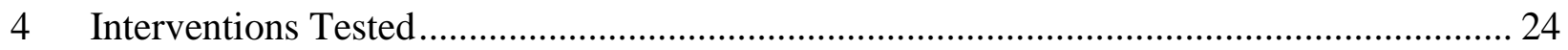




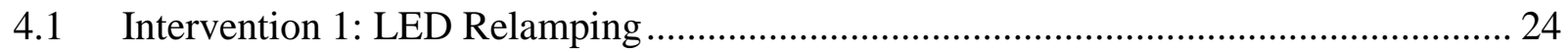

4.2 Intervention 2: Window Retrofit ..................................................................... 25

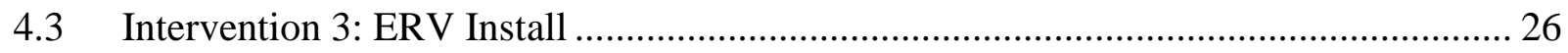

4.4 Intervention 4: Chiller Upgrade ....................................................................... 26

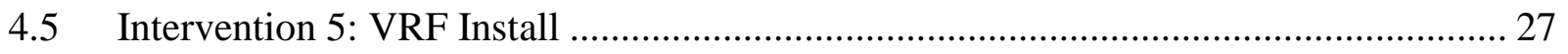

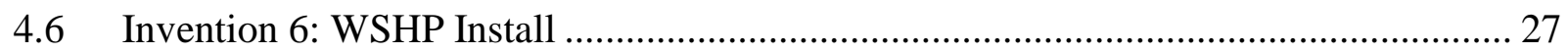

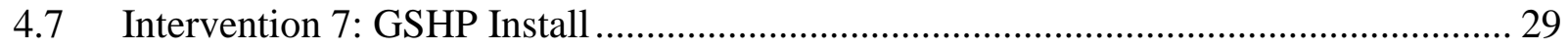

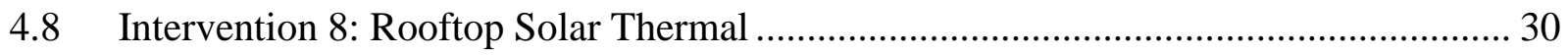

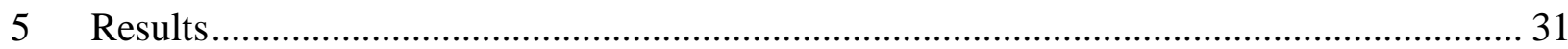

5.1 Data Collection and Typology Selection ......................................................... 31

5.2 Baseline Model Creation ................................................................................ 33

5.3 Intervention Impacts on Building End-Uses and Total Energy …............................ 33

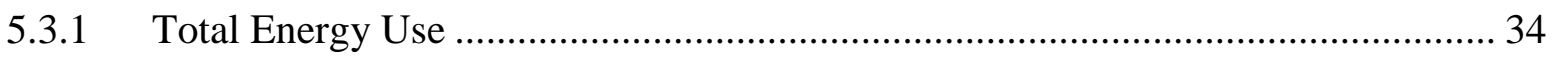

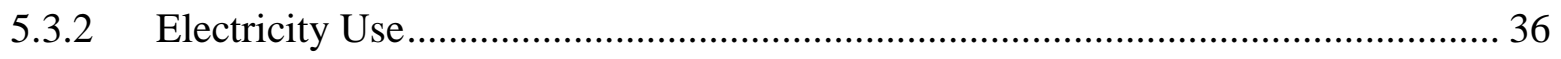

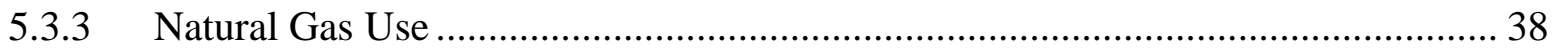

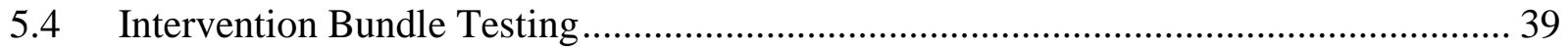

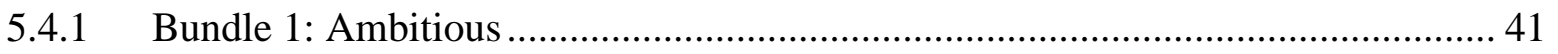

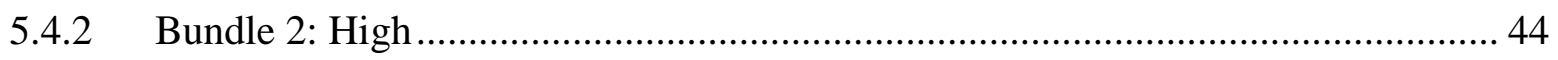

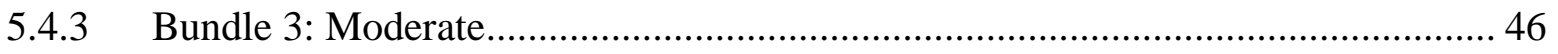

5.5 Bundle Impacts on Total Energy at the District Scale ........................................... 48 
5.6 Bundle Impacts on Total GHG Emissions at District Scale

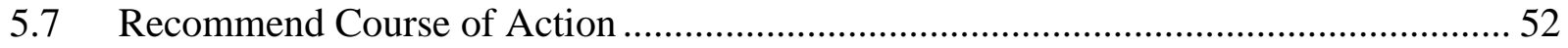

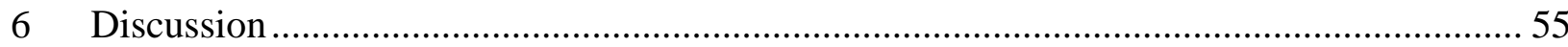

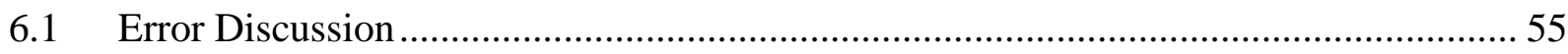

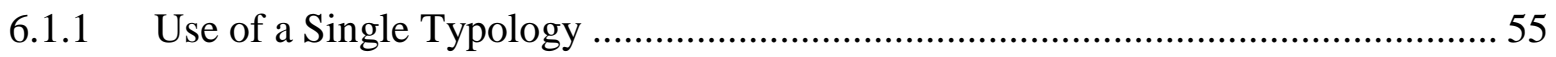

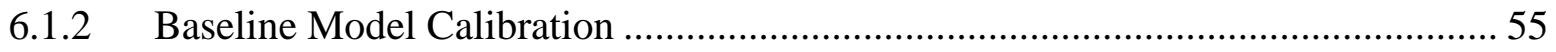

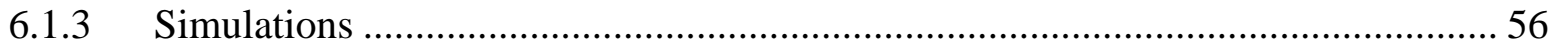

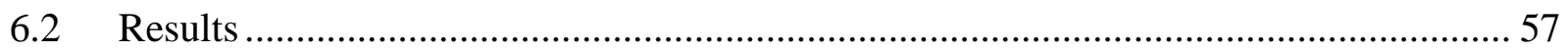

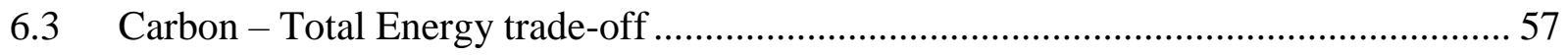

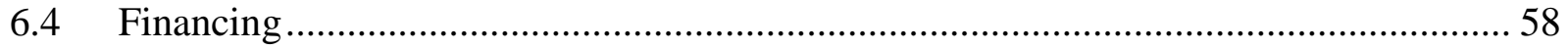

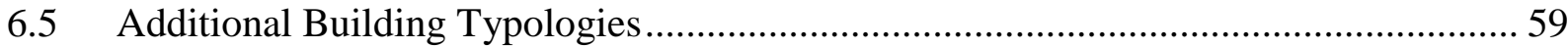

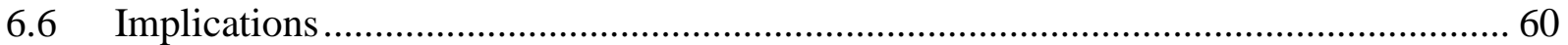

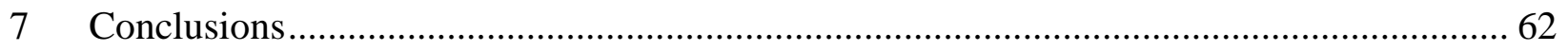

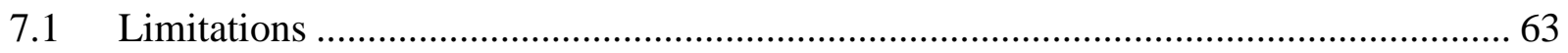

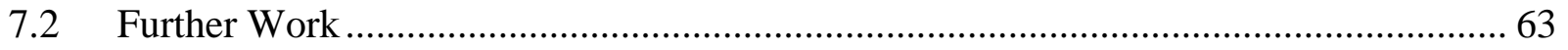

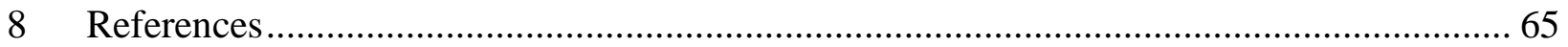




\section{Introduction}

As climate change becomes an increasingly significant challenge in ensuring the stability of the global biotic and abiotic systems in place, it is crucial we consider every aspect of consumption to maintain a sustainable method of anthropogenic operation and growth. Specifically, in 2010 the energy expenditures in building operation contributed to $10 \%$ of greenhouse gas emissions directly linked to climate changes occurring (IPCC, 2014). In response to this, the 2030 Districts Network is a visionary effort in attempting to mitigate climate change currently being driven in part by our built environment through aggressively reducing carbon emissions produced by their construction and operation (2030 Districts, 2018). The committed metropolitan centers have pledged to reduce greenhouse gas emissions by transitioning their urban cores into high-performance building districts. As part of the network, Toronto has set the goal of cutting their district-wide building emissions in half, by the year 2030. Additionally, by 2030 any new buildings within the district will operate with zero emissions.

In part of achieving the goals set forth, it is necessary to appraise the current stock of buildings within the district and quantify energy consumption trends, to determine the most efficient manner of accomplishing the task. Through a deeper understanding of the existing built environment, we are better equipped with finding solutions, extrapolating retrofit scenarios, and communicating the significance of the task at hand to both the general public and private stakeholders involved in the project. Further to this, a more transparent communication of energy expenditures in buildings to the occupants themselves helps to comprehend impacts on a personal level, and aid in developing behavioral changes essential to reducing energy loads. In the broader context, more insight into the overall energy use patterns throughout the district can provide us with opportunities to implement designs that may not have been apparent at the 
individual scale, thus contributing to a synergistic framework of building operation, working towards achieving the goals which will have longstanding impacts on a global level.

\subsection{Research Objective}

The objective of this project is to develop shallow, medium, and deep retrofit options for a building typology dominant in the 2030 district. These retrofit scenarios will be referenced upon energy use intensities exhibited by the baseline building simulation models developed, in order to determine opportunities to maximize GHG reductions.

\subsection{Research Questions}

To complete this objective, the work is to be guided by the following research questions:

1. What are the impacts of individual interventions on building energy consumption and associated GHG emissions?

2. From a GHG reduction standpoint, which combinations of interventions have the potential to achieve moderate, high, and ambitious energy savings? 


\section{Background}

The following sub-sections discuss the development of building energy model simulations, building retrofit solutions, and how they are currently brought together for achieving more accurate estimations of results in reaching energy reduction goals. This discussion aims to outline currently existing technologies, in order to identify knowledge gaps that this research paper focuses on addressing.

\subsection{Building Energy Models}

Building energy models (BEMs) have been in development since the 1970's, utilizing physical input properties such as geometry, materials, and heating, ventilation and air conditioning (HVAC) systems to estimate heating, cooling, and electricity loads (Kim, 2017). When paired with dynamic weather inputs, BEM simulations can be useful in determining the energy required for maintaining specific criteria of building performance, while under the impact of external variables such as occupancy, weather, and infiltrations (Coakley, 2014). A variety of BEM software programs (e.g. BLAST, DOE-2) have been in existence for decades, providing users with the ability to simulate the impression retrofit measures will have on total heating, cooling, and electricity loads (Crawley, et al., 2008). In 2008, the United States Department of Energy (DOE) developed a set of commercial reference BEM's utilizing EnergyPlus software, comprised of 16 building typologies which represent approximately $70 \%$ of the commercial buildings in the US (Deru, et al., 2011). These publicly available BEMs were created to provide consistent baselines for comparison of simulation outputs, in order to analyze the impacts of design alterations, such as retrofit measures or new technologies (Deru, et al., 2011). 


\subsection{Energy Conservation and Greenhouse Gas Reduction Strategies}

Energy conservation measures (ECMs) provide the opportunity to achieve reductions in total building energy uses, through making alterations to the buildings characteristics, such as replacing windows or adding insulation, thereby improving thermal resistance and reducing energy losses (Difs, 2010). Additionally, HVAC systems can be upgraded to increase the efficiencies of the equipment responsible for maintaining indoor air quality and temperature conditions necessary for occupant comfort (Siddharth, 2011). While ECMs may be applied to buildings for the purpose of reducing energy use and resulting utility expenditures, retrofits may be directly aimed towards reducing or removing greenhouse gas emitted on site. Measures such as this would predominantly involve the transition from an HVAC system utilizing a fossil fuel burning boiler (e.g. natural gas) to a system entirely reliant on electricity. These improvements are focused on what is classified as demand side, which intend to reduce the amount of primary energy required to operate a building (Lundström, 2016). Alternatively, there exists potential to increase efficiency in supply side technologies, which involve the production, transmission, distribution and exchange of heat and electricity between buildings and infrastructure (Lundström, 2016). Depending on methods of production, supply side technologies typically involve greenhouse gas emissions as a consequence of energy derived from decentralized sources such as coal (Tamimi, 2013). Due to this, ECMs have the potential to reduce energy uses and indirectly associated GHG emissions from supply side sources (Lundström, 2016). In order to quantify the effects of an ECMs impact on GHG emissions, it is necessary to understand the sources of power generation specific to the location of the building (Zakeri, 2015). Building on a sustainability approach, ECMs may also be implemented with cost considered, in order to determine optimal long-term financial gains from savings due to reduced utility costs from 
improved building technologies (Tan, 2016). A study by Tan, et al (2016) presents a model for quantifying the effects of ECMs when using both financial and environmental objectives as considerations for achieving optimized gains in energy savings. In this manner, it is possible to present solutions for building owners that have the potential to produce both financial and environmental improvements in building operation (Tan, 2016).

\subsection{Urban Building Energy Models}

While traditional BEMs can provide designers with guidance on an individual level, there requires more effort into integrating them into a larger scale for the consideration of energy management at a district wide scale (Reinhart \& Cerezo Davila, 2016). As described by Reinhart and Davila, urban building energy models (UBEMs) represent an emergent tool, which can offer direction for these 'meta' level decisions, by incorporating citywide data on building energy consumption. Unfortunately, individual simulation of every building within a district requires an exorbitant amount of time and resources, therefore archetypical building models can be validated in order to represent the existing stock of structures in its entirety. By aggregating validated archetypical building models with existing Geographic Information Systems (GIS) data, UBEMs can provide an understanding of the big picture trends in building energy use across a city (Reinhart \& Cerezo Davila, 2016). This information can provide us with the ability to analyze the most effective method of reducing energy use within metropolises, via building retrofit measures, or otherwise (Ballarini, et al., 2014). An example of this approach was observed in the 2009-2012 Typology Approach for Building Stock Energy Assessment (TABULA) project conducted by the Intelligent Energy Europe program, which effectively described prototypical residential building typologies respective to the thirteen countries involved in the study (Ballarini, et al., 2014). Considering either "standard" or "advanced" retrofit scenarios, the 
TABULA project was able to describe building energy demands across the nations and present the most effective potential impacts of these retrofit scenarios, with cost optimal considerations (Ballarini, et al., 2014). Further to this, UBEMs are also able to inform us of what specific building typologies within a district are currently operating in the most inefficient manner. Determining a specific typology to focus energy retrofit measures upon ensures the greatest potential energy saving impacts, while also providing an opportunity to reduce capital costs due to economies of scale, when prescribing the materials and techniques required in performing a bulk number of retrofits across an entire district (Gupta \& Gregg, 2018).

\subsection{Public Web Based Urban Energy Models}

Hosting UBEMs in a public web-based format provide an opportunity to inform individual users of potential ECMs that can be applied to particular building typologies, even presenting payback periods of various ECM scenarios (Chen, et al., 2017). This application may entice building owners to pursue retrofit projects themselves, while at minimum providing users with a more informed perspective of building energy uses and their context within a district (Chen, et al., 2017). A version of this approach, City Building Energy Saver (CityBES), was released for public use in 2017, providing users the ability to evaluate ECM scenarios on 940 office and retail buildings in northeast San Francisco (Chen, et al., 2017). Similar to CityBES, the Toronto 2030 Platform tool compiles energy data profiles of buildings within the downtown core, allowing users to benchmark their performance amongst others (2030 Districts, 2018). Electricity, natural gas, district heating, deep lake water-cooling, and water use intensities are exhibited for a variety of building typologies, giving insight to where the greatest reductions can be made within the district (2030 Districts, 2018). Further to this, the platform enables users to upload energy 
models of buildings in the design stage, outputting the specific requirements for achieving standards of LEED, TGS, OBC SB-10, 2030 Challenge, TGS and HPNC (2030 Districts, 2018).

In light of this literature review, the following knowledge gaps have been identified: a lack of empirical building energy model data concerning the impact of interventions on office buildings in the Toronto context, and an understanding of potential effects when combining interventions into stratified bundles for energy and GHG emission reduction scenarios. These are addressed in this investigation through the creation of a representative Toronto office building energy model, the simulation of various energy conservation measures and greenhouse gas reduction strategies, and the synthesis of said strategies into bundles, presenting avenues towards reaching the objectives setforth in the Toronto 2030 District. 


\section{Methodology}

This research aimed to determine the potential paths to achieving goals set forth in the Toronto 2030 District. As such, the building typology with the highest overall impact was targeted, and studied to determine interventions for alleviating impacts at various scales. These interventions were then hypothetically applied to all buildings of the specific typology, in order to quantify the cumulative reductions. A workflow of the research is shown in Figure 1. As described in the objective, the intent was to develop three increasingly effective scenarios for reducing GHG emissions across the district. These scenarios involve combinations of interventions (i.e. bundles) possible for implementation on existing Toronto office buildings, at varying degrees of effectiveness. Through a feed forward selection of interventions, the bundles were created to present clients with potential methods to reach 2030 District initiatives. Beginning with a baseline "Large Office" energy model, the forward selection approach began with no variables applied to the model, testing the addition of each intervention stepwise. Beginning with the most significantly impactful intervention, and repeatedly applying the next most significant intervention, this process was performed for all applicable interventions, as long as a benefit from their inclusion was observed. This method proved useful for determining which interventions were the most impactful, and at what point adding additional interventions provided negligible benefits, or may not become cost optimal. The method proved more useful than a backward elimination, which begins with applying all interventions and removing each stepwise, as the forward selection provided more insight to the optimal combination and number of interventions that provide substantial reductions in GHG emissions, at a cost optimal level. By demonstrating what reductions specific building alterations make, building owners have a clear depiction of the work required, and may be more inclined to pursue them. Furthermore, this 
information is valuable to public policy makers tasked with developing grants and subsidies aimed at reducing GHG emissions and energy uses in buildings.

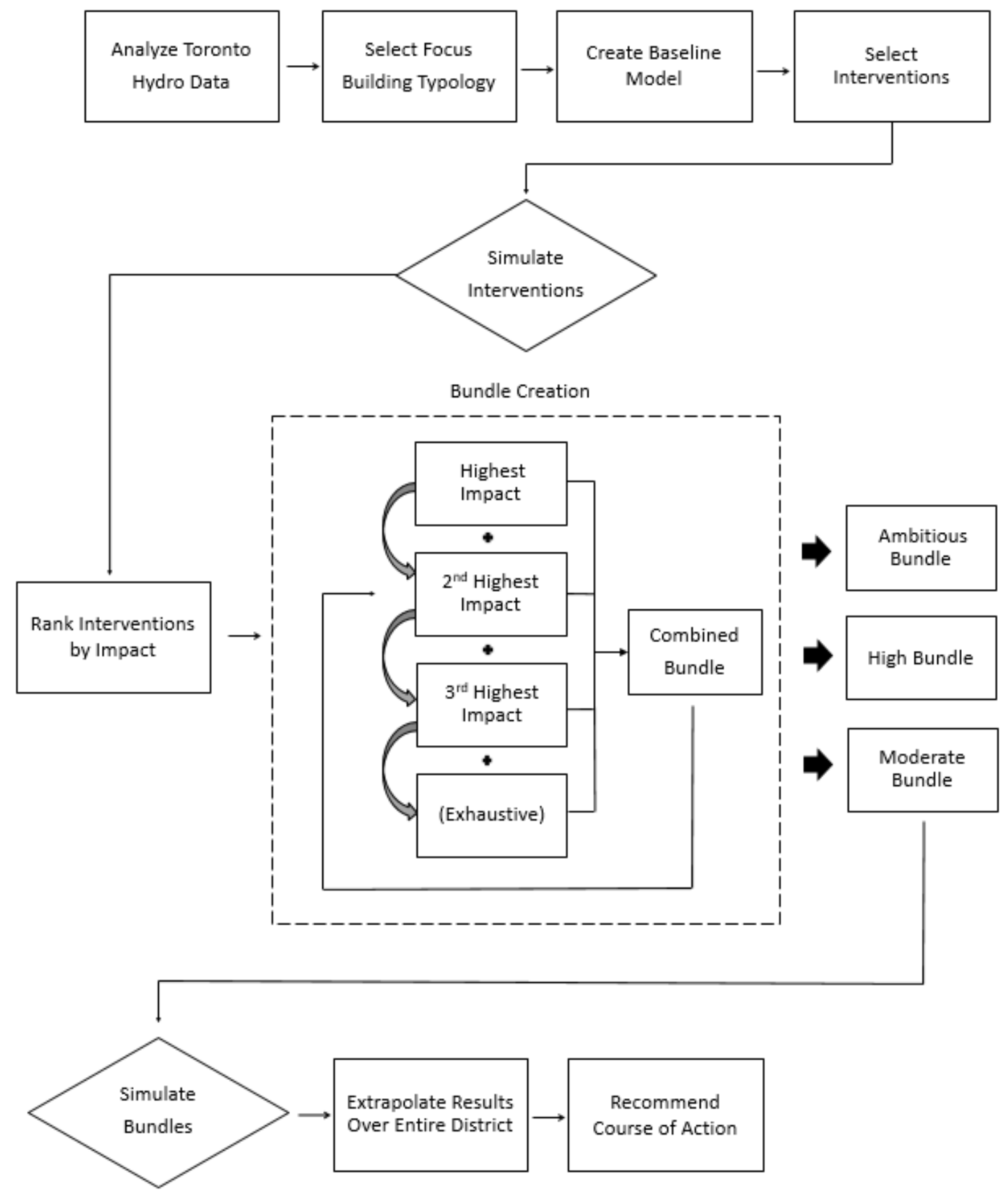

Figure 1 Methodology Overview 


\subsection{Data Collection and Typology Selection}

Data acquired from Toronto Hydro was originally disseminated in a variety of specific building typologies. For ease of analysis, similar building typologies were grouped into more broad categories, allowing for a better understanding of the overall energy use trends in the district. The data analyzed was entirely electricity use, provided in a total per month basis in kilowatt hours $(\mathrm{kWh})$, for the year of 2017 . The total electricity use per each building typology was calculated for the entirety of the year, and ranked in order of percentage of the whole district usage. The building typology with the most dominant electricity use was then selected for analysis.

\subsection{Baseline Model Creation}

In order to evaluate potential ECM impacts, a baseline energy model of a typical Toronto large office building was required. In previous work completed by the U.S Department of Energy (DOE), a collection of sixteen existing commercial reference building models were created, including a "Large Office" type model which deemed suitable for application in this study. In addition to unique building typologies, separate models of each typology were designed to suit sixteen different distinct climate zones, in their respective cities. As the principal informant for North America's building design with respect to climatic influences, the ANSI/ASHRAE Standard 90.1 "Energy Standard for Buildings Except Low-Rise Residential Buildings" (ASHRAE, 2013) was heavily referenced in producing the building models with characteristics appropriate to their location of construction. In Table 1, the fundamental qualities related to a building model's performance have been synthesized. 


\section{Building Category Descriptions}

\begin{tabular}{|c|l|}
\hline Form & $\begin{array}{l}\text { Conditioned areas, number of floors, aspect } \\
\text { ratio, wall-to-wall ratio, shading devices, and } \\
\text { floor heights. }\end{array}$ \\
\hline Fabric & $\begin{array}{l}\text { Air tightness, materials, glazing systems, and } \\
\text { construction assemblies. }\end{array}$ \\
\hline Program & $\begin{array}{l}\text { Process loads, ventilation rates, occupancy } \\
\text { densities, space activities, domestic hot water } \\
\text { demand, and operating schedules. }\end{array}$ \\
\hline Equipment & $\begin{array}{l}\text { Lighting fixtures, HVAC systems, HVAC } \\
\text { efficiencies, and control settings. }\end{array}$ \\
\hline
\end{tabular}

As the DOE report scope was geographically limited to USA, a reference building located within a most similar climate zone to Toronto to be determined. Although Toronto is currently to 5A, it was assumed that during the time of construction majority of the typical large Toronto offices were built as per climate zone 6 conditions at the time, therefore the reference model for the Minneapolis, Minnesota location (designed as per climate zone 6A) was selected (City of Toronto, 2017). Table 2 provides a condensed summary of the baseline models physical characteristics. 


\begin{tabular}{|c|c|c|}
\hline \multirow{6}{*}{ Form } & Floor Area (m2) & 46,320 \\
\hline & Number of Floors (plus basement) & 12 \\
\hline & Aspect Ratio & 1.5 \\
\hline & Glazing Fraction (window/wall ratio) & 0.38 \\
\hline & Shading Devices & None \\
\hline & Floor-to-Ceiling Height (m) & 2.74 \\
\hline \multirow{4}{*}{ Fabric } & Air Tightness (m3/s-m2) & 0.001133 \\
\hline & Materials & See Appendix A, Table A.1 \\
\hline & Glazing U-Value (W/m2-K) & 2.95 \\
\hline & Construction Assembly (Mass Wall, W/m2-K) & 0.408 \\
\hline \multirow{5}{*}{ Program } & Plug Loads (W/m2) & 10.76 \\
\hline & Ventilation Rate (Outdoor Air - cfm/person) & 20 \\
\hline & Occupant Densities (m2/person) & 18.6 \\
\hline & $\begin{array}{l}\text { Domestic Hot Water Demand }(\mathrm{L} / \mathrm{hr} / \text { floor }) \\
{\left[\text { Set temperature }=43^{\circ} \mathrm{C}\right]}\end{array}$ & 80.6 \\
\hline & Operating Schedule & Per ASHRAE 90.1 - 1989 \\
\hline \multirow{5}{*}{ Equipment } & Lighting Fixtures (W/m2) & 16.14 \\
\hline & Heating & Gas Fired Boiler \\
\hline & Cooling & Water Cooled Chillers (2) \\
\hline & Air Distribution & Multizone VAV \\
\hline & HVAC Efficiencies & $\begin{array}{l}\text { Boiler }-70.5 \% \text { eff. } \\
\text { Chiller-5.2 COP }\end{array}$ \\
\hline
\end{tabular}

Baseline model trials were performed utilizing the current version of EnergyPlus (9.0) which required the original DOE model's version (7.2) to be translated into the current version in order for simulations to be performed.

\subsection{Selection of Interventions}

Two sets of interventions were considered - energy conservation measures (ECMs) designed to save total energy use in a building, and greenhouse gas reduction measures (GHGRs) focusing on shifting from $\mathrm{CO} 2$-emitting fuel sources to low-carbon sources. While ECMs provide energy savings, their impact on GHG reduction is indirect, as they only reduce either raw electrical consumption provided off-site by GHG emitting utility sources, or the heating and cooling demands met on-site by GHG emitting HVAC equipment. More attune to 2030 District goals, 
GHGRs attempt to directly reduce or optimally eliminate all GHG emissions occurring on-site, due to the burning of natural gas. In this scenario, the only GHG emissions related to building operation would be associated with energy drawn from the Ontario electrical grid, which for 2017 values, equate to 32 grams of carbon emissions per kWh of energy produced (IESO, 2017).

Due to the high renewable and nuclear production on the Ontario grid, a focus on shifting from natural gas to electricity for heating applications is critical. Table 3 provides a brief depiction of the interventions, as well as a mnemonic, which will be used to refer to each intervention throughout the rest of the paper. More technical descriptions are given in the following chapter.

Table 3-Intervention Descriptions

\begin{tabular}{|c|c|c|c|l|}
\hline & Intervention & Mnemonic & Type & \multicolumn{1}{|c|}{ Description } \\
\hline 1 & LED Relamping & LED & ECM & $\begin{array}{l}\text { Existing light bulbs are replaced higher } \\
\text { efficient LED equivalents }\end{array}$ \\
\hline 3 & Window Retrofit & Window & ECM & $\begin{array}{l}\text { Existing windows are replaced with } \\
\text { higher performing equivalents }\end{array}$ \\
\hline 4 & ERV Install & ERV & ECM & $\begin{array}{l}\text { Energy recovery ventilator installed } \\
\text { onto the existing air loop }\end{array}$ \\
\hline 5 & $\begin{array}{c}\text { Convert HVAC to } \\
\text { VRF }\end{array}$ & VRF & GHGR & $\begin{array}{l}\text { Chiller replaced with a more efficient } \\
\text { equivalent model }\end{array}$ \\
\hline 6 & $\begin{array}{c}\text { Convert HVAC to } \\
\text { WSHP }\end{array}$ & WSHP & GHGR & $\begin{array}{l}\text { Replace the VAV system with a } \\
\text { source heat pump system }\end{array}$ \\
\hline 7 & $\begin{array}{c}\text { Convert HVAC to } \\
\text { WSHP + GSHP }\end{array}$ & GSHP & GHGR & $\begin{array}{l}\text { Replace the VAV system with a WSHP } \\
\text { and a ground source heat pump }\end{array}$ \\
\hline 8 & $\begin{array}{c}\text { GSHP + Solar } \\
\text { Thermal Panel } \\
\text { Install }\end{array}$ & Solar & GHGR & $\begin{array}{l}\text { Install rooftop evacuated tube hot water } \\
\text { solar panel collectors and tie these into } \\
\text { the GSHP system to reduce boiler top- } \\
\text { up. }\end{array}$ \\
\hline
\end{tabular}




\subsection{Intervention Testing}

The baseline simulation and all subsequent iterations were performed using the climate dataset "Canadian Weather Year for Energy Calculation" (CWEC) file for the Toronto location (Numerical Logics, 1999). This dataset contains hourly weather inputs which represent approximated averages derived from the "Canadian Energy and Engineering Data Sets" (CWEEDS) data gathered from 1935-1995 (Numerical Logics, 1999). Each iteration was built upon the original baseline file, where the necessary alterations or additions were implemented using either the built in EnergyPlus IDF Editor, or via external text editing software (i.e. Notepad). More complex interventions required the use of additional software with a graphical user interface (GUI) in order to model full mechanical systems prior to exporting to .idf for simulation in EnergyPlus. OpenStudio was selected as a suitable modelling software, as the DOE "Large Office" commercial reference building model was available for download from the whole building component library. Each individual simulation was ran separately for a duration of one year, using the EnergyPlus default timestep of six. This value describes the number of times the zone heat balance model calculation is occurring per hour, therefore zonal heat transfer and load calculations occur every 10 minutes throughout the simulation (Department of Energy, 2015).

\subsection{Intervention Bundle Creation and Evaluation}

Each intervention was simulated individually to determine the net energy reduction when compared to the baseline, then ranked in order of effectiveness. In order to evaluate the potential degrees of energy reduction possible, the combined effect of multiple interventions (i.e.

"bundles") on the baseline were tested. Bundles were created using a "feed forward" method, where mutually exclusive interventions were cumulatively applied to the baseline model in 
ascending order of effectiveness, starting with the intervention that provided the largest total energy reduction, followed by adding the next most effective intervention. A basic workflow of this methodology can be seen in Figure 2 below.

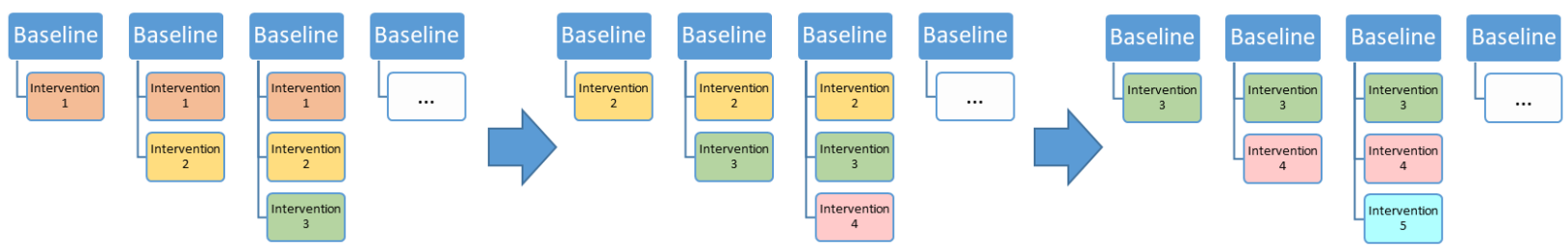

\section{Figure 2 - Bundle Testing Workflow}

In certain scenarios, additional interventions were unable to be applied due to overlap or incompatibility with existing interventions. Table 4 displays the compatibility of each intervention, where compatible pairs are indicated with " $\checkmark$ " and shaded green, and incompatible pairs indicated with " $\mathrm{X}$ " and shaded red.

Table 4 - Intervention Compatibilities

\begin{tabular}{|c|c|c|c|c|c|c|c|c|}
\hline & GSHP & VRF & Solar & LED & Window & WSHP & Chiller & ERV \\
\hline GSHP & & X & $\checkmark$ & $\checkmark$ & $\checkmark$ & $\checkmark$ & X & $\checkmark$ \\
\hline VRF & X & & $x$ & $\checkmark$ & $\checkmark$ & X & X & $\checkmark$ \\
\hline Solar & $\checkmark$ & X & & $\checkmark$ & $\checkmark$ & $\checkmark$ & $\checkmark$ & $\checkmark$ \\
\hline LED & $\checkmark$ & $\checkmark$ & $\checkmark$ & & $\checkmark$ & $\checkmark$ & $\checkmark$ & $\checkmark$ \\
\hline Window & $\checkmark$ & $\checkmark$ & $\checkmark$ & $\checkmark$ & & $\checkmark$ & $\checkmark$ & $\checkmark$ \\
\hline WSHP & $\checkmark$ & $x$ & $\checkmark$ & $\checkmark$ & $\checkmark$ & & $x$ & $\checkmark$ \\
\hline Chiller & $x$ & $x$ & $\checkmark$ & $\checkmark$ & $\checkmark$ & $x$ & & $\checkmark$ \\
\hline ERV & $\checkmark$ & $\checkmark$ & $\checkmark$ & $\checkmark$ & $\checkmark$ & $\checkmark$ & $\checkmark$ & \\
\hline
\end{tabular}

Following simulations, three bundles were selected to represent "moderate", "high", and "ambitious" energy saving scenarios, presented in units of $\mathrm{kWh} / \mathrm{m}_{2}$. 


\subsection{Extrapolate ECM Impacts}

The EUI $\left(\mathrm{kWh} / \mathrm{m}^{2}\right)$ of each bundle was multiplied by the total gross floor area (GFA) of all the buildings categorized as "Office" within the district, based on data provided by the Toronto 2030 District Platform (2030 Districts, 2018). For each bundle, the aggregate kWh value was compared to the estimated total energy use of all "Office" buildings in the district, providing flat rate and percent reduction in energy use per each bundle scenario. Additionally, the bundles impact on office buildings in terms of the total energy use all buildings types in the district was calculated, as a percent reduction.

\subsection{Evaluate GHG reductions}

The anticipated amount of GHG emissions for each bundle was calculated by converting both the electricity and natural gas use into equivalent intensity, in a grams of $\mathrm{CO}_{2}$ per meter squared value. The same procedure used in Section 3.6 was used to determine both a flat value and percent reduction in GHG emissions, when compared to both the total "Office" building emissions, and as part of all building typologies in the district.

\subsection{Determine Intervention Scenarios and Recommend Course of Action}

Following analysis of all intervention and bundle impacts, the recommended course of action is described for a best-case scenario, and pragmatic approach. The best-case scenario describes the suggested changes that can to be made in order to achieve District 2030 goals, while the pragmatic approach suggests interventions that are anticipated to have the greatest cost effectiveness. 


\section{Interventions Tested}

The following subsections provide an in-depth description of each intervention tested.

\subsection{Intervention 1: LED Relamping}

This ECM involves a 1:1 replacement of the existing lamps with a higher efficiency LED lamps. With more widespread adoption, LED lamp manufacturers have developed equivalent products that are able to directly replace existing lamps, without the need for installing a new luminaire. Therefore, an LED relamping project requires no modifications to the ceiling cavity and can be completed quickly with minimal costs or alterations in appearance. For example, typical recessed and pendant office lights use a pin based 50W MR16 incandescent lamp, which can be directly replaced with 11W LED lamps (National Resources Canada, 2017). Moreover, roughly $50 \%$ of lighting in commercial spaces consist of the troffer-style luminaire (U.S. DOE, 2018). The troffer luminaire exists in the form of a 2'x4' fixture installed within suspended ceiling grid panels, most commonly containing either T12 or T8 fluorescent lamps which can also be directly replaced with LED equivalents at a matched efficacy (U.S. DOE, 2018). In EnergyPlus, internal electrical lighting loads are located within the "Lights" class, quantified by the Lighting Power Density (LPD) as expressed by a Watts per meters squared value. The DOE determined a uniform LPD for reference models with multiple space types based upon the product of the allowable unit power density prescribed by Table 6.5 of ASHRAE 90.1 - 1989, thereby utilizing the same LPD value of $16.14 \mathrm{~W} / \mathrm{m} 2$ for all zones of the Large Office model (Deru, et al., 2008). As the input field for lighting uses an LPD value without of any descriptive text, the actual type of lamps (e.g. linear fluorescent, halogen incandescent etc.) the model attempts to emulate can only be inferred, therefore the ECM LPD value is approximated, 
representing the conversion of all lamps to an LED equivalent. Drawing upon the work of Chen et al. (2017), LED retrofits in a large office building are estimated to achieve an overall LPD of $6.46 \mathrm{~W} / \mathrm{m} 2$.

\subsection{Intervention 2: Window Retrofit}

This ECM increases the thermal resistance of the exterior glazing. The baseline model utilizes a fixed glazing assembly, in a ribbon style, as seen in Figure 3 below.

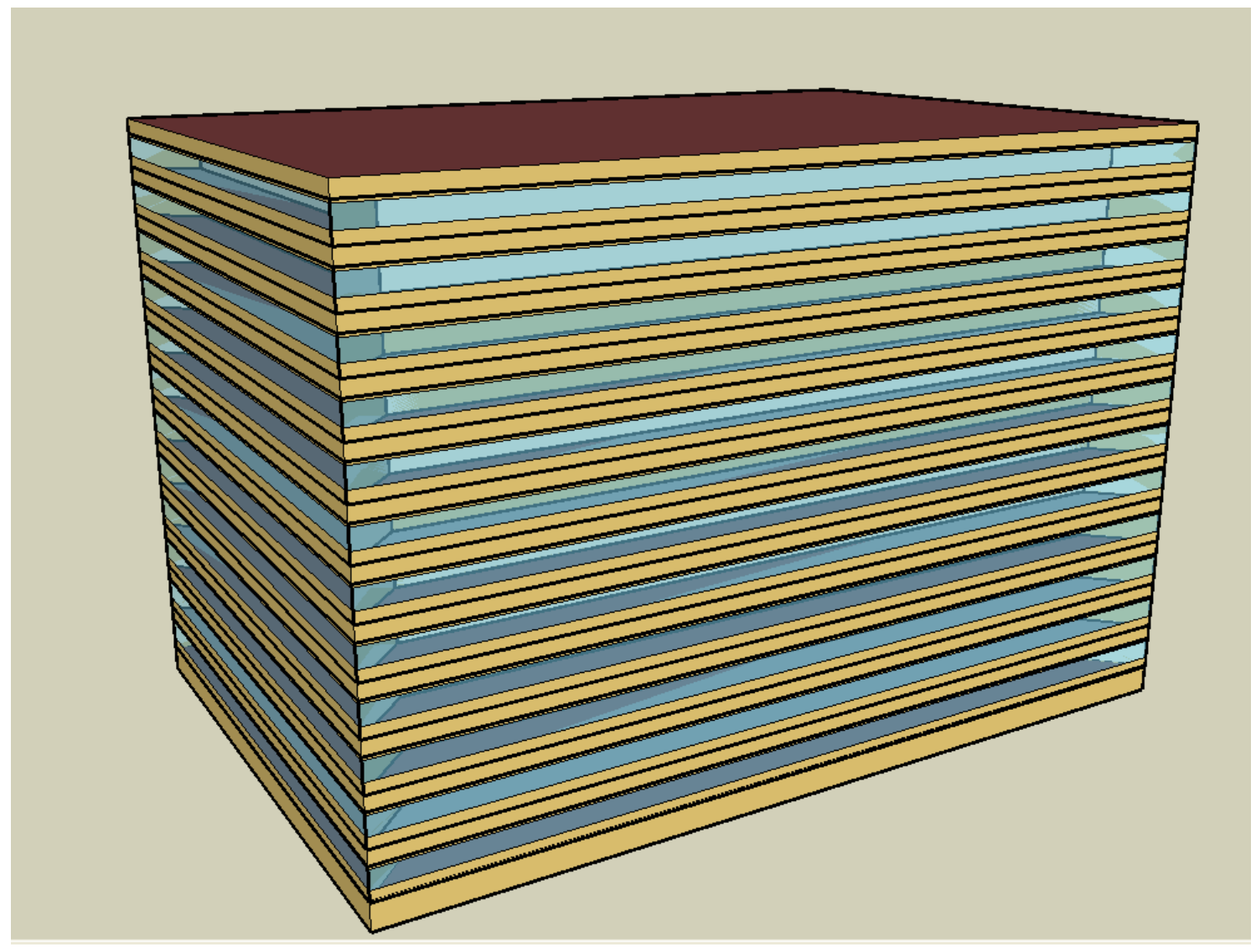

Figure 3 - Baseline Model Design

Only the U-factor (W/m2-K) was altered in this ECM, as any adjustments to the window to wall ratio would require more intrusive changes to the exterior wall assembly, being a more extensive amount of work. The baseline model uses the "SimpleGlazingSystem" object, which describes 
the entire glazing system with a single U-factor, including film coefficients, as opposed to quantifying individual layers. This ECM represents a minimally intrusive retrofit scenario where the existing structural framing surrounding the window is unaltered; the original windows are replaced with an equivalently sized upgrade. The baseline model uses a National Fenestration Rating Council (NFRC) rated U-Factor of $2.95 \mathrm{~W} / \mathrm{m} 2-\mathrm{K}$, which represents the entire window (i.e. frame, spacer, and glazing). A U-Factor of $0.38 \mathrm{~W} / \mathrm{m} 2-\mathrm{K}$ was selected for simulating a window retrofit ECM, drawing upon ASHRAE 189.1 - 2014 Prescriptive Fenestration Requirements, for the maximum recommended U-Factor in fixed metal frame windows for climate zone 5 .

\subsection{Intervention 3: ERV Install}

This ECM involves the installation of a 200-Watt rotary Energy Recovery Ventilator (ERV) unit onto the existing air-handling unit. The unit can be incorporated into the existing HVAC system, providing air-to-air heat exchange between exhaust and supply ducting. The ERV object was added into the baseline model with the object "HeatExchanger:AirToAir:SensibleAndLatent", where a full text description can be seen in Appendix B. The ERV was modelled to work in conjunction with the existing economizer through specifying "ModulateFlow" in the "Controller:OutdoorAir" object, thereby suspending heat exchange during periods where the economizer is active.

\subsection{Intervention 4: Chiller Upgrade}

This ECM represents a direct replacement of the two electric water-cooled chillers with higher efficiency models. The baseline chillers have a 300-ton capacity, utilizing a screw type compressor, each with a coefficient of performance (COP) of 5.2. Table 6.8.1C of ASHRAE 
90.1 - 2004, which states minimum efficiencies of water-cooled chillers, directed the initial COP selected by the DOE. Equivalently sized mag-bearing type chillers with seasonal COP's of 8 were selected as replacements, and applied to the baseline model for simulation (City of Toronto, 2017).

\subsection{Intervention 5: VRF Install}

This intervention involved a full replacement of the VAV HVAC system into a variable refrigerant flow (VRF) system describe system with a dedicated outdoor air supply (DOAS), thereby eliminating all natural gas use. Previous work completed at the Florida Solar Energy Centre, and Electric Power Research Institute was used for incorporation into the large office baseline model (Raustad, 2013). The study completed by Ruastad et al (2013), involved validating the manufacturer's performance data of a Mitsubishi PURY-P72THMU VRF system with their lab results, and applying the values to various DOE reference models. The VRF system operates on four condensing units with a COP of 2.75, alongside supplemental electric baseboard heating with $97 \%$ efficiency. Additionally, the VRF system was able to provide heat recovery, simultaneously cooling and heating multiple zones in the simulation.

\subsection{Invention 6: WSHP Install}

Again, this intervention involved a full replacement of the VAV system, converting to a water source heat pump (WSHP) system with a DOAS. The heat pumps implemented had a heating COP of 4 , and a cooling COP of 6.45, with the condenser water loop being supplemented by a natural gas boiler with an efficiency of $90 \%$. This WSHP system and the subsequent interventions were created using OpenStudio, and exported for simulation in EnergyPlus to obtain results. As the OpenStudio model was unable to include heat recovery in the WSHP 
system, a manual calculation was performed post-simulation to calculate the approximate the potential energy savings due to heat recovery, based on a heat transfer efficiency of 95\% (Trane, 2018). Dynamic heating and cooling loads were created using the EnergyPlus .idf editor, where the "Output:Meter" class was modified to include the objects "PlantLoopHeatingDemand:HVAC" and "PlantLoopCoolingDemand:HVAC", with the reporting frequency set to "Detailed". The outputted .csv "Output:Meter" file provided the heating and cooling demand in Joules, every 10 minutes for the duration of simulation. A combination of excel functions were implemented in the "Output:Meter" file to define the net HVAC demand and calculate the potential for energy recovery within the system, roughly as follows:

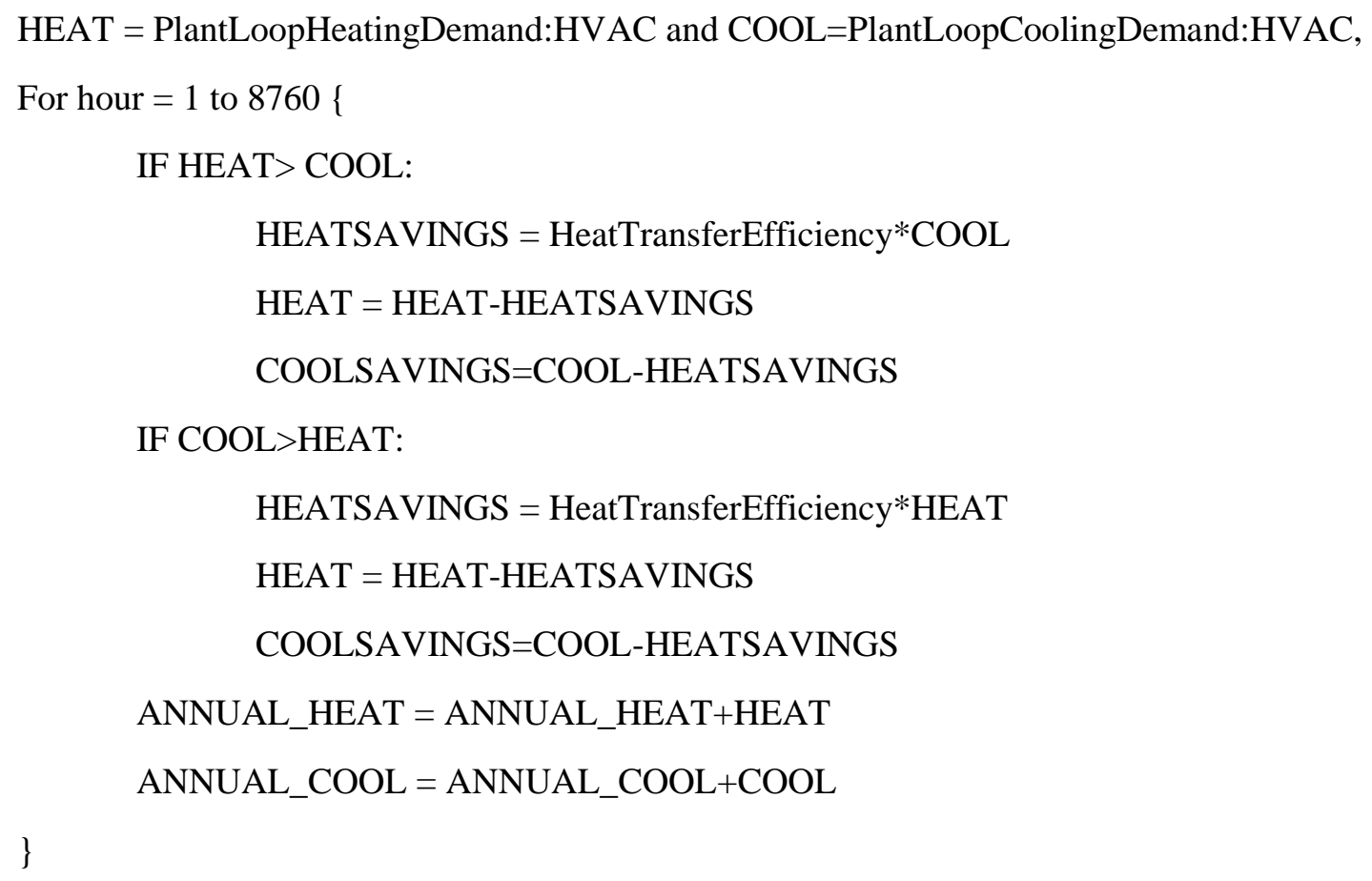




\subsection{Intervention 7: GSHP Install}

This intervention builds upon the WSHP intervention, through the addition of a ground source heat pump (GSHP) system that works in conjunction with the WSHP condenser loop. The GSHP system utilizes 200 vertical boreholes at a length of $60.96 \mathrm{~m}$ and radius of $0.15 \mathrm{~m}$, housing Ushape pipes with a grout conductivity of $1.298 \mathrm{~W} / \mathrm{m} * \mathrm{~K}$, and a flow rate of $0.0033 \mathrm{~m} 3 / \mathrm{s}$. The dimensionless G-function reference ratio of the system is 0.0005 . This function is a numerical model for describing the temperature distribution and change over time of the borehole walls, and resulting fluid entrance and exit temperatures (Liu, 2006). The G-function is dictated by the borehole field configuration (i.e. ratio of spacing to depth) and borehole thermal resistance (Yavuzturk, 1999). A basic schematic of the GSHP system can be seen below in Figure 4.

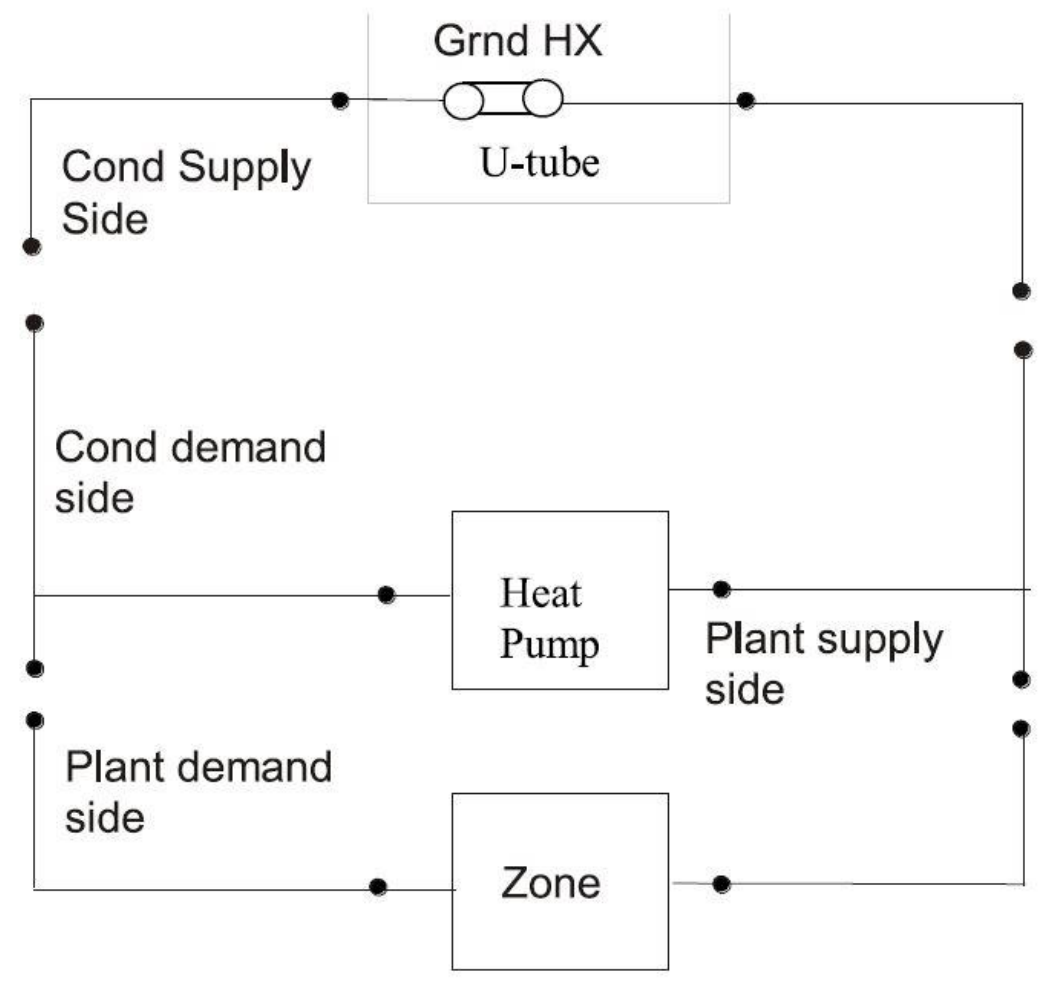

Figure 4 - GSHP system configuration (Murugappan, 2002) 


\subsection{Intervention 8: Rooftop Solar Thermal}

Intervention 8 involves the installation of evacuated tube (ET) solar thermal panels on the rooftop, with associated thermal storage. The total roof area of the baseline building is $3563 \mathrm{~m}^{2}$, which accommodates an estimated $1782 \mathrm{~m}^{2}$ area for ET panels (Weger, 2018). The ET panels are $3 \mathrm{~m}^{2}$ in size, with copper pipes operating at a flow rate of $0.78 \mathrm{~L} / \mathrm{m}$, providing a peak power output of $1.32 \mathrm{kWh}$ (Weger, 2018). A detailed technical description of the ET panels can be seen in Table A.2 of the Appendix A. 


\section{Results}

This chapter consists of simulation results for each individual intervention, the three bundles of interventions, and the bundles impact when extrapolated over the entire district. The reductions are presented in terms of both energy use and GHG emissions in units of ekWh, and $\mathrm{MtCO}_{2} \mathrm{e}$, respectively.

\subsection{Data Collection and Typology Selection}

Due to availability of data, electricity use was the sole metric used to select the building typology focused on in the study. Monthly electricity consumption data was provided by Toronto Hydro and broken down for 42 specific building typologies. Figure 5 displays the building typologies using the most electricity within the 2030 district. In this figure, it is clear that the "Office" building type constitutes the largest portion of the total electricity usage within the district, embodying approximately $25 \%$ of the total electricity use for the year of 2017 . This is followed by condominium residential units, colleges/universities, hospitals, malls/plazas, residential houses, retail, apartments, residential suites, and hotel/motels. The office typology utilized twice the total energy use of condominiums and three times the amount of colleges and universities, therefore representing the building typology with the greatest potential for reduction impacts and was therefore chosen for this study. While this methodology relied exclusively on electricity use as a metric for selecting the studied building typology, given the consistency of building envelope requirements across building typologies, it was felt that offices provided a valuable case study focus to determine the maximum amount of impact on GHG emission reductions in the district. Overall, the high electricity usage experienced from office buildings appears to be a strong indicator for high energy use overall, when considering all typologies in the building 
portfolio. Furthermore, as office-related GHG reductions are determined in this study, their impacts can be expected to be applicable to other typologies in the district.

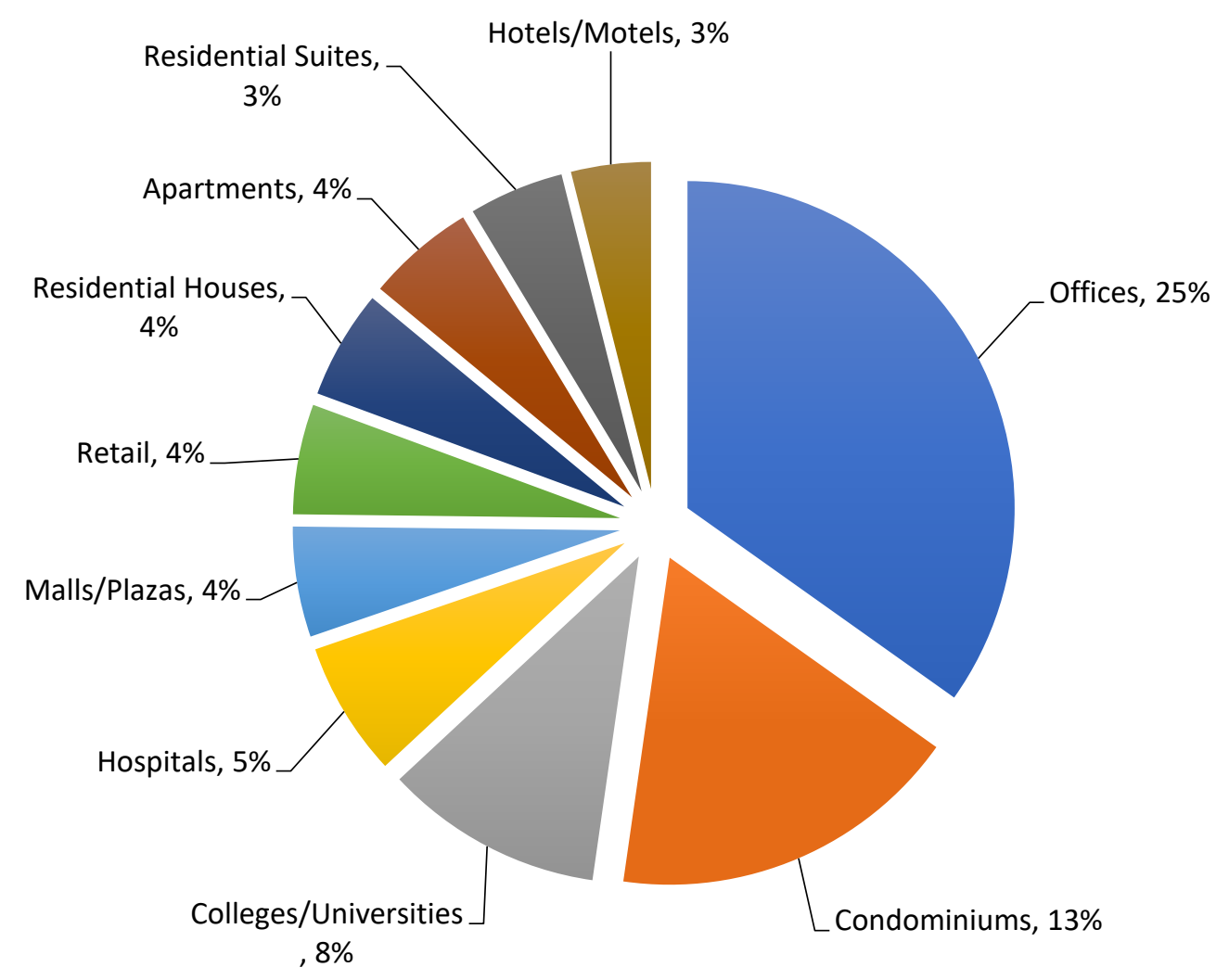

Figure 5 - Top Ten Electricity Consumers by Building Type within Toronto's 2030 district 


\subsection{Baseline Model Creation}

As the original DOE reference model was created in a previous version (v7.2) of EnergyPlus in translation were observed in initial simulations, as chiller electricity uses were underreported by $55 \%$ when compared to original simulation output variables provided by DOE. This was found to be due to a recurrent error where the Plant Loop and Condenser Loop temperatures fell below the minimum allowable value, which was remedied by reducing the minimum values to an acceptable level. The adjustments made to the baseline file can be seen in Appendix B. Simulation results for the corrected baseline model provided an energy use intensity (EUI) of $198.72 \mathrm{kWh} / \mathrm{m}^{2}$, as compared to the original EUI of $188.14 \mathrm{kWh} / \mathrm{m}^{2}$, equating to a 5.6 percent decrease.

\subsection{Intervention Impacts on Building End-Uses and Total Energy}

Each intervention was tested individually on the baseline file and analyzed to determine impacts separately in terms of electricity end use, natural gas end use, and total energy use. 


\subsubsection{Total Energy Use}

Figure 6 compares the effectiveness of each intervention, providing the total energy use reduction with reference to the baseline. In this analysis, energy use refers to the total end use of all forms of energy used in the building (i.e. natural gas and electricity). Reduction percentages were derived from EnergyPlus output tables, which provide end use values in GJ for all forms of building energy end use. The VRF and GSHP interventions were able to achieve the largest total energy savings, while the ERV intervention was the least impactful.

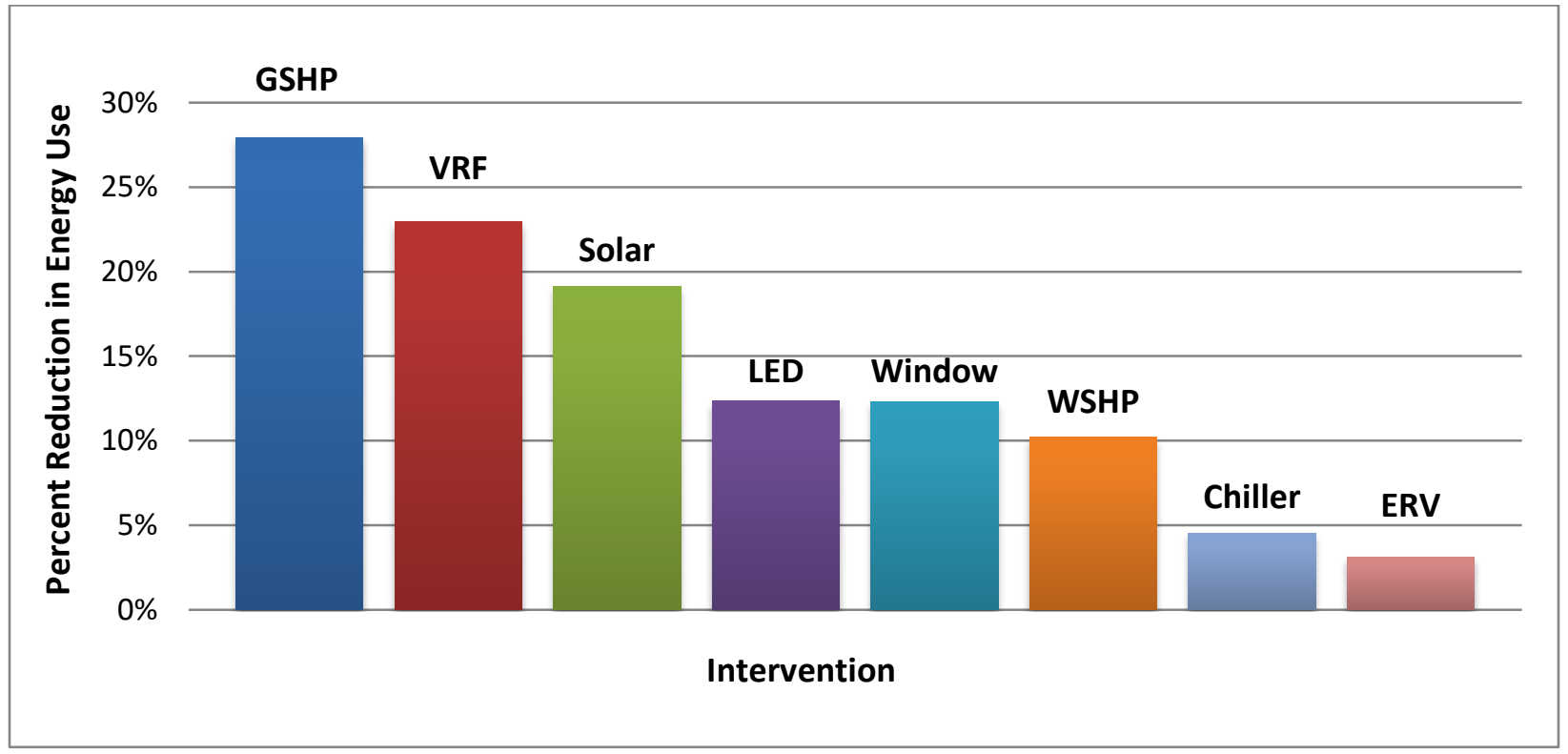

Figure 6 - Intervention Impacts on Total Energy End Use, as percent reduction from baseline.

Table 5 displays the interventions resulting EUI and percent reduction from baseline. Each of the interventions was applied independently onto the baseline file, to determine the overall reduction in energy use, in units of $\mathrm{kWh} / \mathrm{m}^{2}$, and as a percent reduction on the total energy use observed when compared to the original baseline model. Every individual intervention was simulated separately for the duration of one year, using the CWEC weather file for the Toronto location. After each intervention was properly implemented into the baseline EnergyPlus model, simulated 
for a full 8760 hour, yearlong period, the results of the each simulation were gathered and ranked individually in order of effectiveness, as seen in Table 5. The interventions were ranked in order of effectiveness to aid in determining which combinations of interventions could be applied to the baseline model. By sorting each intervention's impact on the baseline model, the degree of effectiveness became more apparent, guiding the selection of interventions as applied into bundles, outlined in Section 5.4. After ranking each interventions impact as a percent reduction compared to the baseline EUI, the clearly more impactful interventions were found to be related to entire HVAC system replacements. This was evident in the GSHP and VRF interventions, as they accomplished reductions on the total energy use of roughly $28 \%$ and $23 \%$, respectively. While each intervention tested was implemented individually on the baseline model, the GSHP intervention inherently included a WSHP system as a function for transporting the energy transferred from the ground boreholes. Additionally, it should be noted that the results of the solar thermal intervention were applied as a flat value $(\mathrm{kWh})$ in the reduction of total energy uses that could be achieved through the rooftop panel installation, as informed by data collected by the research conducted by Wegner (2018). In this intervention we were to assume the rooftop solar thermal units were able to be integrated into the hot water loop of the existing baseline model's HVAC system, with the inclusion of a hot water storage tank. 
Table 5 - Ranked Intervention Reduction on Total Energy End Use

\begin{tabular}{|c|c|c|}
\hline Intervention & $\begin{array}{c}\text { Reduction on } \\
\text { Total Energy Use }\end{array}$ & EUI (kWh/m $\mathbf{~}^{\mathbf{})}$ \\
\hline GSHP & $27.94 \%$ & 143.19 \\
\hline VRF & $22.93 \%$ & 153.15 \\
\hline Solar Thermal & $19.15 \%$ & 160.67 \\
\hline LED Relamping & $12.33 \%$ & 174.22 \\
\hline Window Retrofit & $12.30 \%$ & 174.28 \\
\hline WSHP & $10.20 \%$ & 178.45 \\
\hline Chiller Upgrade & $4.52 \%$ & 190.12 \\
\hline ERV Install & $3.10 \%$ & 192.56 \\
\hline Baseline & $0 \%$ & 198.72 \\
\hline
\end{tabular}

\subsubsection{Electricity Use}

The electricity end use from each individual source in the building is broken down for ECMs and GHGRs in Figures 7 and 8, respectively. This provides insight regarding the specific responses an intervention has on the individual electricity loads in the building. The ECM interventions made no impact on electrical heating load, as they included no alterations to the HVAC system, which relies solely on natural gas for the heating demand. Notably, the window retrofit intervention produced an increase in the required cooling demand, likely due to a greater amount of internal heat retention. The VRF, WSHP, and GSHP interventions induced an electrical cooling load, derived from the operation of the heat pumps and associated mechanical equipment. Additionally, these three HVAC based interventions produced a decrease in the pump loads, as these load were accounted for as a function of the cooling and heating loads. Exterior lighting, interior equipment, and exterior equipment were not impacted by any of the interventions. 


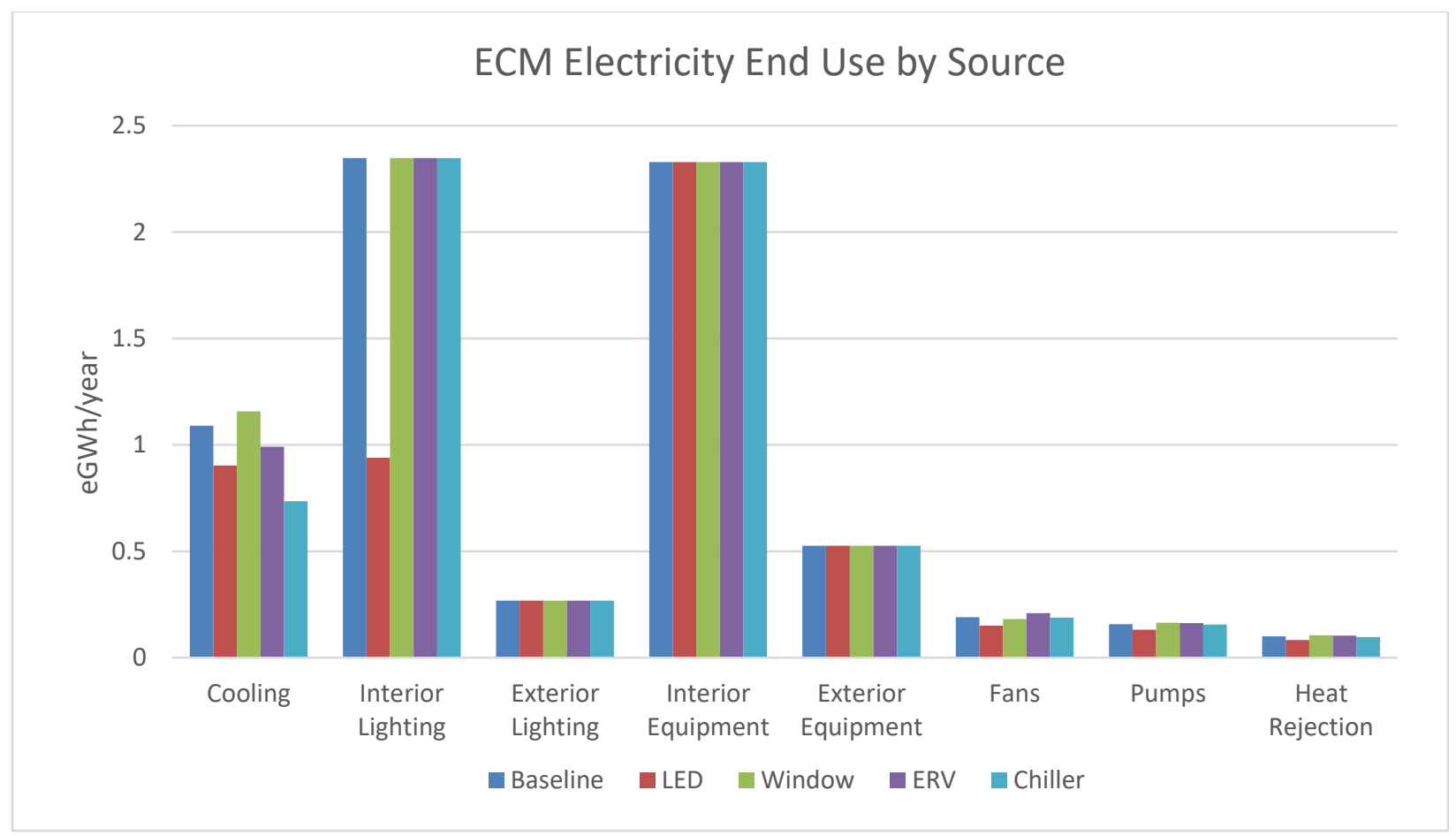

Figure 7 - ECM Impact on Electricity Use by Source

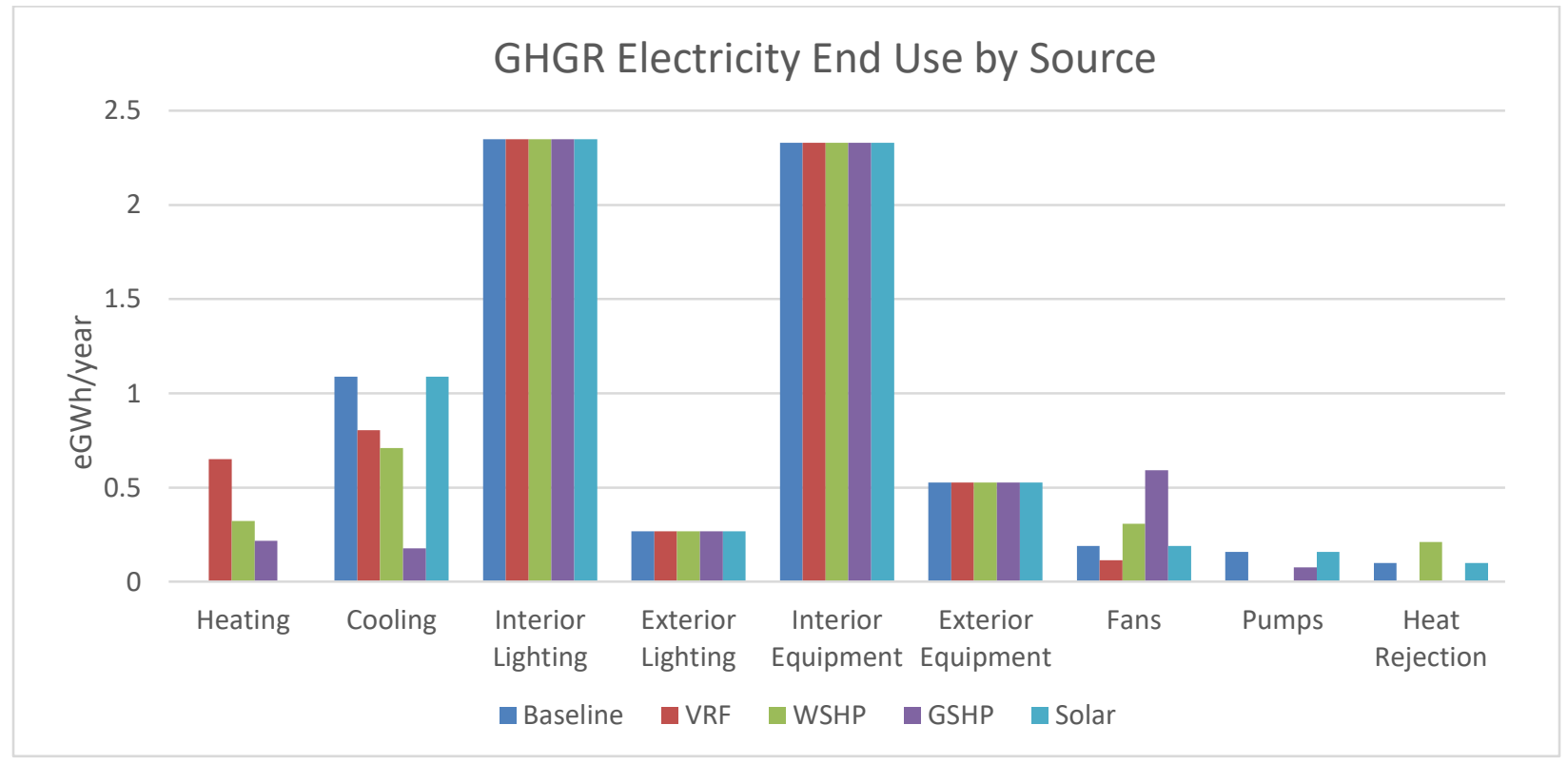

Figure 8 - GHGR Impact on Electricity Use by Source 


\subsubsection{Natural Gas Use}

Figure 9 compares the impact of each intervention on natural gas use when applied to the baseline model. Since EnergyPlus reports all end uses in gigajoules (GJ), the end use values were first converted into equivalent kilowatt-hours (ekWh), to a natural gas volume, based on a conversion factor of $1 \mathrm{~m}^{3}$ natural gas per $10.395 \mathrm{ekWh}$ (Union Gas, 2018), and finally to equivalent tonnes of $\mathrm{CO}_{2}\left(\mathrm{tCO}_{2} \mathrm{e}\right)$, using a conversion factor of 1874.6 grams $\mathrm{CO}_{2} \mathrm{e}$ per $\mathrm{m}^{3}$ of natural gas burned (Enbridge, 2017).

The solar thermal, window retrofit, GSHP, WSHP, and VRF interventions were able to significantly decrease the total natural gas end uses and subsequent GHG emissions, crucial to the directives of the 2030 District goals. Notably, the VRF intervention was able to eliminate site GHG emissions, as the system is entirely reliant on electricity in its operation. While the WSHP and GSHP systems include terminal units that rely on electricity to exchange heat, their condenser loops occasionally require additional heat input to maintain set-point temperatures, which is provided by a natural gas top up boiler. The LED intervention created an increase in natural gas use, which was understood to have been due to loss of waste heat originally generated by incandescent lighting. The Chiller intervention made no impact on the amount of natural gas use, as its operation only has an influence on the cooling load of the building, which is electricity based. The Solar intervention provided a massive decrease in the natural gas end use, near levels achieved by the VRF and GSHP interventions, which involve an entire HVAC system replacement. This is due to the fact the intervention specifically targets reductions in the heating load through the introduction of heat gathered from sunlight, providing what is essentially free energy. 


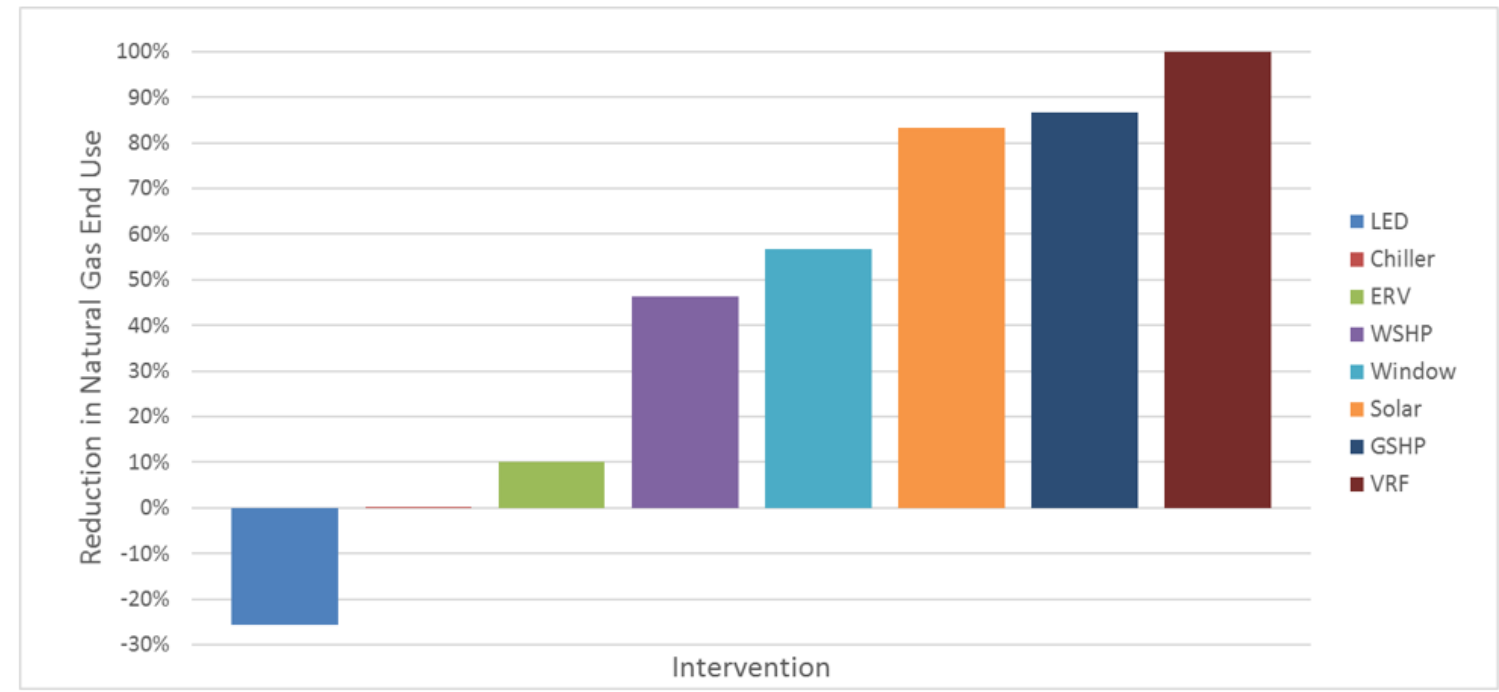

Figure 9 - Intervention Impact on GHG Emissions

\subsection{Intervention Bundle Testing}

Each bundle was created by applying interventions stepwise, providing increasing reductions in the greenhouse gas emissions with each additional intervention, as can be seen in Figure 10.

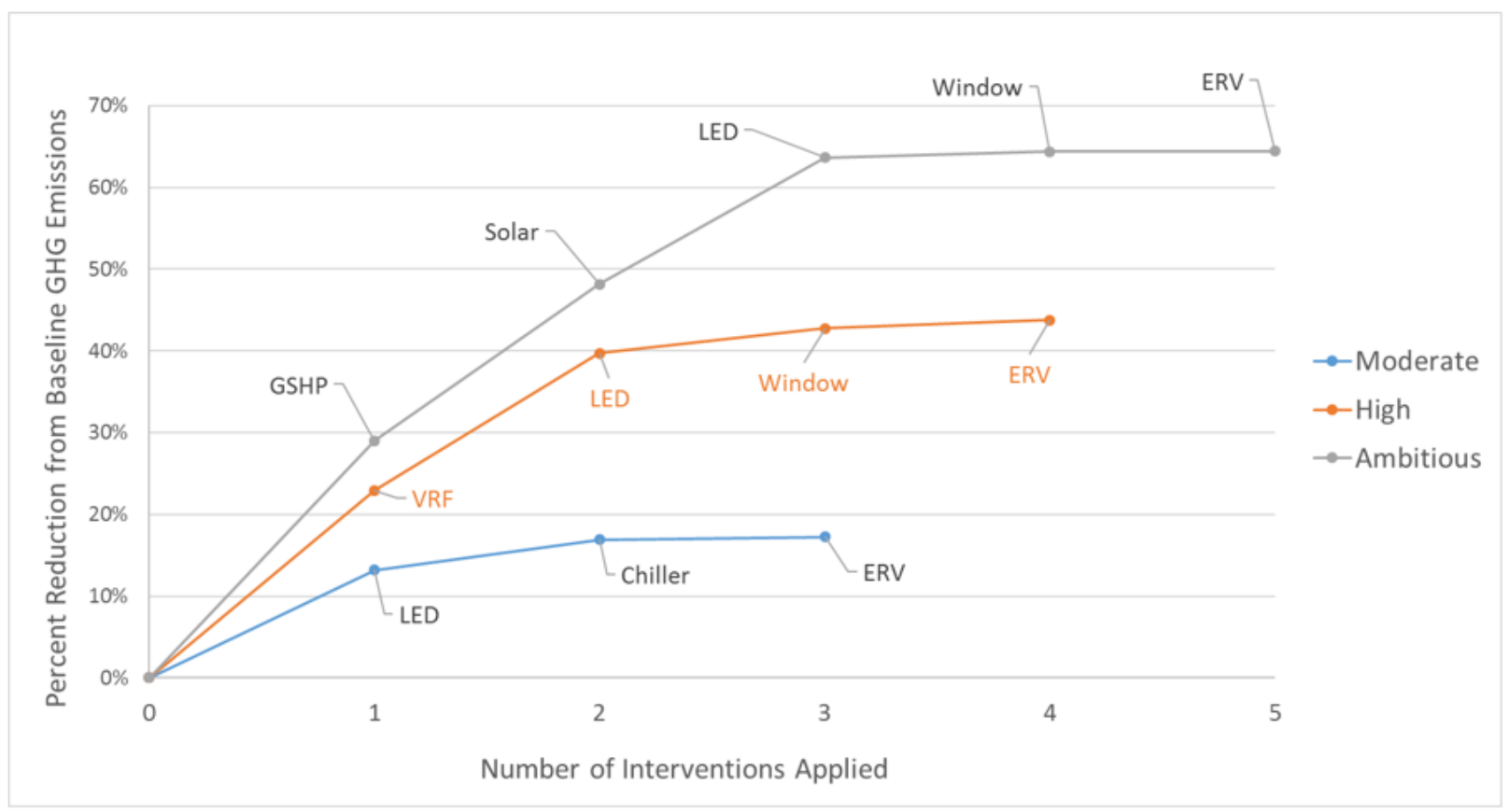

Figure 10 - Bundle Development GHGI Impacts 
While the initial interventions provide a large reduction in the GHG emissions, each additional intervention provides incrementally less savings. In every scenario of bundle development, there existed a point where the additional interventions have such a diminished effect on the GHGI, and their application may not be justified if the cost and time to install them is taken into consideration. For each bundle, it appears the final two interventions applied produce an inadequate level of savings. This is especially true for the window retrofit intervention, as it is an invasive installation, requiring a great deal of time and labour to perform, while also potentially disrupting the occupants of the building. While the implementation of the ERV is less invasive, as a final additional intervention it appears to be highly ineffective, as it attempts to improve efficiency of an already highly efficient HVAC system. This intervention appears to better suited as a stand-alone upgrade on existing buildings, which run on inefficient HVAC systems where there is greater potential to recapture return air energy.

Following the application of interventions that reduce the cooling and heating loads of the building, the dominant source of energy use in the baseline model is interior equipment, as seen in Figure 7 and 8. While additional interventions can improve 'thermal' performance, as this facet of building operation becomes more efficient, there exists a diminishing ability to produce further improvements. At which point, the means to achieving further reductions in the building's overall energy use may be better directed at reducing interior equipment loads. This may be remedied by upgrading to equipment with higher efficiencies, reducing overall plug loads, or improving building controls, all of which involve research beyond the scope of this study. 


\subsubsection{Bundle 1: Ambitious}

The ambitious bundle was developed to represent an action plan where building owners are attempting to meet the goals of the Toronto 2030 District directly. In this scenario, the ambitious bundle is the most aggressive combination of the interventions initially tested, that could all be integrated into a typical Toronto Office tower. The selection of the interventions used in this bundle was initially vetted to ensure they were compatible with each other, as outlined previously in Table 5. For this bundle of interventions to be considered functional as a group of retrofits applied to a building collectively, they were spot checked to ensure compatibility. This bundle provides a perspective into what combination of interventions are able to achieve the maximum amount of GHG emission reductions possible for offices in the Toronto 2030 District. Accordingly, the ambitious bundle represents an assertive approach to meeting larger goals outside of the directives of the Toronto 2030 District, related to global climate change mitigation, through heavily reducing both GHG emissions, and energy use intensities in metropolitan buildings. Bundle 1 thus represents the most aggressive possible combinations of interventions, where the decrease in EUI and GHGI for each additional intervention can be seen in Table 6. The units used to represent the reduction in total building GHG emissions were converted into a kilograms of $\mathrm{CO}_{2}$ per meter squared value $\left(\mathrm{kgCO}_{2} / \mathrm{m}^{2}\right)$. This unit was used to quantify the bundle of interventions impact on GHG emission intensity (GHGI), per square meter of building floorspace. This provided an ability to extrapolate the total potential GHG emission reduction, if applied to every 'Office' type building contained within the district. 
Table 6 - Bundle 1: Ambitious Development

\begin{tabular}{|c|c|c|c|c|}
\hline \multirow{2}{*}{ Interventions Applied } & \multicolumn{2}{|c|}{ Total Building Energy } & \multicolumn{2}{c|}{ Total Building GHG Emissions } \\
\cline { 2 - 5 } & $\begin{array}{c}\text { Bundle EUI } \\
\left(\mathbf{k W h} / \mathbf{m}^{\mathbf{2}}\right)\end{array}$ & \% Reduction & $\begin{array}{c}\text { Bundle GHGI } \\
\left(\mathbf{k g C O 2} / \mathbf{m}^{\mathbf{2}}\right)\end{array}$ & \% Reduction \\
\hline None (Baseline) & 198.72 & $0 \%$ & 6.36 & $0 \%$ \\
\hline Add GSHP & 141.05 & $29.0 \%$ & 4.51 & $29.0 \%$ \\
\hline Add solar & 134.96 & $32.1 \%$ & 4.32 & $48.18 \%$ \\
\hline Add LED & 104.18 & $47.6 \%$ & 3.33 & $63.67 \%$ \\
\hline Add window retrofit & 102.76 & $48.3 \%$ & 3.29 & $64.38 \%$ \\
\hline Add ERV & 102.62 & $48.40 \%$ & 3.28 & $64.45 \%$ \\
\hline
\end{tabular}

While this bundle includes every compatible intervention, the later interventions - namely the inclusion of the Window and ERV - have limited benefit, on the order of $0.7 \%$ and $0.1 \%$, respectively, in terms of electricity use and $0.7 \%$ and $0.1 \%$ for greenhouse gas emissions. These were modeled to ensure that the forward feed selection bundle creation methodology was completed. While the full list of interventions represents a "maximum" potential case given the selected interventions, it does not represent an ideal cost optimal scenario. Instead, the following set of interventions is recommended: GSHP, Solar, and LED. These interventions were able to create the largest impacts on the overall GHGI reductions, when compared to the baseline file. In these cases, there were substantial reductions in GHG emissions observed at each stage of their addition to the baseline model. Specifically, the GSHP system was able to achieve a $29 \%$ reduction in GHGI, reducing the overall emissions by nearly one third, when compared to the baseline model's original HVAC system emission totals. Further to this, the addition of the solar intervention provided an added $19 \%$ reduction on the GHGI when applied alongside the GSHP system. Correspondingly, the inclusion of the LED intervention was able to provide an increased $15 \%$ reduction in the GHGI when bundled with the GSHP and solar interventions. These results confirmed which interventions are most beneficial to the goals related to the Toronto 2030 District. While these three interventions are unique in their application to office buildings, and 
require varying degrees of invasiveness for their installation, they are clearly impactful enough to be considered for obtaining aggressive reductions in the emissions that currently can be attributed to the operation of large office buildings in the Toronto context. It should be noted that when initially implementing the solar with the GSHP intervention there was a diminished effect when compared to the solar intervention's individual effect. This was due to the fact the GSHP system was already able to achieve large reductions in the natural gas loading that was overcompensated for by the solar intervention, resulting in energy production that is potentially underutilized in the system. After adjusting calculations to consider the potential for energy storage by the solar collectors, there was a more substantial impact, which justified its inclusion. This calculation adjustment also demonstrates why there was a discrepancy observed between the EUI and GHGI percentage change when adding the solar intervention to the Ambitious bundle. There was only a 3\% reduction in the EUI after adding the solar intervention, but a $19 \%$ reduction observed in the GHGI. The large jump in GHGI percentage reduction when adding the solar intervention provided substantial impact on the amount of natural gas use, and consequent volume of GHG emissions. By harnessing heat gathered from solar radiation on rooftop panels, the solar intervention reduced a substantial amount of heating required during the winter months. This highlights the high potential for solar thermal collectors to be integrated into large office towers in Toronto. Despite conventional understanding of the application of solar thermal, there appears to be an unrealized opportunity for solar collectors to be applied to cold climate conditions, in order to offset high heating demands during winter months, as experienced in Toronto. 


\subsubsection{Bundle 2: High}

Bundle 2 represents another potential combination of interventions that produces a high degree of improvement in efficiency. This set of interventions was developed to present building owners with an ability to improve their building efficiency, and potentially reduce their overall electrical utility expenditures from building operation. In this manner, Bundle 2 demonstrates a scenario where a high initial investment in retrofits could provide returns over time, especially observed with commercial offices, where electrical expenditures become costly when aggregated over time. As the additional intervention applied, there are diminished returns provided, where the additional levels of retrofit appear to become minimally beneficial. The incremental decrease in EUI and GHGI for each additional intervention can be seen in Table 7.

Table 7 - Bundle 2: High Development

\begin{tabular}{|c|c|c|c|c|}
\hline \multirow{2}{*}{$\begin{array}{c}\text { Interventions } \\
\text { Applied }\end{array}$} & \multicolumn{2}{|c|}{ Total Building Energy } & \multicolumn{2}{c|}{ Total Building GHG Emissions } \\
\cline { 2 - 5 } & $\begin{array}{c}\text { Bundle EUI } \\
\text { (kWh/m2) }\end{array}$ & \% Reduction & $\begin{array}{c}\text { Bundle GHGI } \\
\text { (kgCO2/. } \mathbf{~}^{\mathbf{}} \text { ) }\end{array}$ & \% Reduction \\
\hline None (Baseline) & 198.72 & $0 \%$ & 6.36 & $0 \%$ \\
\hline Add VRF & 153.15 & $22.9 \%$ & 4.90 & $22.9 \%$ \\
\hline Add LED & 119.77 & $39.7 \%$ & 3.83 & $39.7 \%$ \\
\hline Add window retrofit & 113.72 & $42.8 \%$ & 3.64 & $42.8 \%$ \\
\hline Add ERV & 111.79 & $43.7 \%$ & 3.58 & $43.7 \%$ \\
\hline
\end{tabular}

Upon the initial conversion of the HVAC equipment to an electrically driven VRF HVAC system, the first intervention was able to provide an approximate $23 \%$ reduction in the overall GHGI when compared to baseline. The addition of the LED upgrade intervention provided an additional 17\% reduction in GHGI. Following this, the addition of a Window upgrade intervention contributed an increased 3\% GHGI reduction. Finally, the ERV intervention provided a minimally additional $1 \%$ reduction on the GHGI. As was observed with the Ambitious bundle, the final two interventions provided substantially less reductions in the 
overall GHGI; therefore the practicality of their inclusion may be questionable to building owners seeking to reduce either EUI or GHG emissions.

Overall, "Bundle 2: High" achieved a GHGI 20.6\% less effective in comparison to "Bundle 1: Ambitious". Where Bundle 2 is lacking is in terms of its potential for integration into district heating systems. As opposed to one including a WSHP design, a VRF based bundle would be neglecting an opportunity to connect to district thermal energy systems currently available in Toronto. This facet of energy savings has becoming an increasingly emphasized, as described throughout the Toronto Zero Emissions Framework, and makes Bundle 2 a less attractive option (City of Toronto, 2017). Conversely, this bundle may represent an optimal case for the design of buildings specifically in Ontario, as our electrical grid has become more reliant on cleaner energy. Between 2001 and 2014, Ontario completed the phase out of coal fired plants in Ontario, meaning the carbon emissions related to electricity consumption has decline substantially (Government of Ontario, 2019). As of 2014, 60\% of Ontario's electricity is derived from Nuclear power, which operates without the carbon emissions that were being experienced through the electrical generation by coal fired plants (Government of Ontario, 2019). With this in mind, the uses of HVAC systems entirely reliant on electricity become more desirable, as they are powered through clean energy. Further to this, as renewable resources (i.e. solar panels, wind turbines) become more widely adopted and integrated into a smart grid system, VRF systems such as this may be better suited to an electrical infrastructure grid that works more harmoniously with renewable resources that generate electricity. Additionally, the conversion of an HVAC system reliant purely on electricity - as such with a VRF system - may be more financially viable for building owners on the whole. While district heating systems have been known to work efficiently, and have been successfully implemented in cities such as Copenhagen, they require 
connections to transmission lines contained underground (Bach, 2016). This may present a large barrier to entry for building owners, as a great deal of planning and excavation work is required to make the required connections to link onto a district heating network in the city. With a VRF HVAC system, the equipment is contained within the building, and may present an option that requires a much less invasive approach.

\subsubsection{Bundle 3: Moderate}

Bundle 3 presents a scenario which may be more achievable for owners of existing large office buildings. The moderate bundle represents a more modest scale of intervention for building owners, when compared to the extensive amount of retrofits involved in Bundles $1 \& 2$. In order to present a viable avenue towards reaching goals that are related to the 2030 District directives, the modest bundle requires much less of a building overhaul, it may be more readily applied to across a large number of office buildings across the district. In this scenario, there would still be great deal of energy savings achieved, if a large volume of buildings were to perform the described interventions. If a bundle such as this can be presented to building owners with practicality, and price in mind, there is a much higher potential for them to consider performing the described interventions. Furthermore, this combination of interventions applied was selected due to their ease of implementation, as they are consistent with most building retrofits currently being performed. Each intervention is able to be installed in a timely manner onto the existing systems without a great deal of intrusion to the building, or its occupants. Specific to the Chiller intervention, this ECM can be applied when a replacement is already required, providing an opportunity to make substantial improvements at a minimally increased cost. The incremental decrease in EUI and GHGI for each additional intervention can be seen in Table 8. 
Table 8 - Bundle 3: Moderate Development

\begin{tabular}{|c|c|c|c|c|}
\hline \multirow[b]{2}{*}{ Interventions Applied } & \multicolumn{2}{|c|}{ Total Building Energy } & \multicolumn{2}{|c|}{ Total Building GHG Emissions } \\
\hline & $\begin{array}{l}\text { Bundle EUI } \\
\left(\mathrm{kWh} / \mathrm{m}^{2}\right)\end{array}$ & $\%$ Reduction & $\begin{array}{l}\text { Bundle GHGI } \\
\left(\mathrm{kgCO} 2 / \mathrm{m}^{2}\right)\end{array}$ & $\%$ Reduction \\
\hline None (Baseline) & 198.72 & $0 \%$ & 6.36 & $0 \%$ \\
\hline Add LED & 172.57 & $13.2 \%$ & 5.52 & $13.2 \%$ \\
\hline Add Chiller & 165.12 & $16.9 \%$ & 5.28 & $16.9 \%$ \\
\hline Add ERV & 164.48 & $17.2 \%$ & 5.26 & $17.2 \%$ \\
\hline
\end{tabular}

As seen in the above table, the LED intervention provided approximately a $13 \%$ reduction in GHGI when applied to the baseline model. Following, the addition of a Chiller upgrade intervention produced an additional 3.7\% reduction in GHGI. This reduction in GHGI was due to a simulated higher efficiency chiller model, which reduced overall energy consumption when providing chilled water for cooling purposes in large office buildings. Again, the addition of an ERV intervention onto the baseline model provided a very minimal reduction in the GHGI, with a less than $1 \%$ improvement. Based on the results compiled in Table 8 , it is again clear that the LED intervention is a highly impactful route towards achieving reductions in associated GHG emissions produced by offices in Toronto. Currently, there may be large office buildings that are operating with the use of inefficient fluorescent or incandescent lightings that could be easily upgraded to equivalent LED models, and provide a reduction in energy use and consequent GHG emissions. Results from the data provided by "Bundle 3: Moderate" affirms there may be simple adjustments to be made on the existing office building stock, that could provide tangible results on the overall GHG emissions experienced in the district. In extension of this, performing a chiller upgrade may be potentially viable for building owners when their existing chiller equipment reaches its end of life. In this situation, if a chiller already requires a replacement, the cost to upgrade to a model with a higher COP can provide additional savings in energy use 
related to cooling demands in office buildings. Economically speaking, the costs associated with upgrading to a high efficiency chiller should be recuperated over time, as the savings experienced from the reduction in electricity costs incurred on a monthly basis eventually will compensate for the initial investment. In addition to the long term financial gain, this provides a positive impact on the amount of associated GHG emissions, as is in line with Toronto 2030 District goals. In summary, Bundle 3 presents a pragmatic approach to reducing energy use and GHG emissions in Toronto office buildings, specific to owners who are looking to reducing their carbon footprint in a more manageable, financially viable, and less intrusive manner than required in Bundles 1 or 2.

\subsection{Bundle Impacts on Total Energy at the District Scale}

Table 9 provides an impression of the potential reduction of total energy use if all office buildings in the district were to have the according bundles applied along with the percent reduction that would be achieved across the district if applied to all office buildings. This presents a potential roadmap to achieving the Toronto 2030 District goal. Given this information, we are better equipped to determine what reductions must be made in the remaining building typologies, for meeting the $50 \%$ reduction in energy use for all existing buildings in the district. It should be noted that the amount of energy savings and percent reductions are when compared to the 2017 energy use totals provided by the 2030 Platform website (2030 Districts, 2018). 
Table 9 - Bundle Impacts on District Energy Use

\begin{tabular}{|l|c|c|c|c|}
\hline & $\begin{array}{c}\text { Total Energy Use } \\
\text { (eGWh) }\end{array}$ & $\begin{array}{c}\text { Total Energy Saved } \\
\text { (eGWh) }\end{array}$ & $\begin{array}{c}\text { Reduction in } \\
\text { Office Building } \\
\text { Energy Use }\end{array}$ & $\begin{array}{c}\text { Reduction in } \\
\text { Total District } \\
\text { Energy Use }\end{array}$ \\
\hline $\begin{array}{l}\text { Office Bundle 1: } \\
\text { Ambitious }\end{array}$ & 889.8 & 1440.2 & $61.8 \%$ & $14.4 \%$ \\
\hline $\begin{array}{l}\text { Office Bundle 2: } \\
\text { High }\end{array}$ & 969.3 & 1360.7 & $58.4 \%$ & $13.6 \%$ \\
\hline $\begin{array}{l}\text { Office Bundle 3: } \\
\text { Moderate }\end{array}$ & 1426.2 & 903.8 & $38.8 \%$ & $9.0 \%$ \\
\hline
\end{tabular}

Based on simulation results, this table utilizes the calculated EUI derived from each bundle's impact on the baseline model, in units of $\mathrm{kWh} / \mathrm{m}^{2}$. After determining the EUI for each bundle, the impact reduction was hypothetically applied to all office floorspace in the district, as provided by the Toronto 2030 Platform values. Using a gross office floor area value of 8,671,000 $\mathrm{m}^{2}$, the EUI of each bundle was used to determine the total amount of energy utilized in a year, if all office spaces were to perform the necessary interventions as described for each bundle. This hypothetical value for the simulated total energy use for one year, post-intervention was then compared to the historical baseline, namely the actual amount of energy used for all offices in the district for the year of 2017. Each bundle provides an estimation of how much energy could be saved in total for each tier of combined interventions.

Bundle 1: Ambitious represented the most aggressive scenario, involving a combination of five interventions, it was able to achieve a $61.8 \%$ reduction in the total energy use, when compared to the total values of energy use for offices in 2017. Next, Bundle 2: High was able to achieve a $58.4 \%$ reduction on energy uses, after applying four interventions together. Finally, Bundle 3: Moderate provided a $38.8 \%$ reduction on office building energy uses, through the combination of three interventions. Examining the impacts, we can see that Bundle 1 provides the largest degree 
of energy reductions, but still requires an auxiliary heating source where the solar insolation is inadequate due to shading effects. This bundle included rooftop solar thermal panels, which were assumed to cover $50 \%$ of the gross roof area, with an adequate degree of solar exposure. In reality, there may be seasonal variations in the degree of solar insolation, or shading effects experience from neighboring buildings. Therefore, an auxiliary heating system would be required to ensure that winter heating demands are always met for the operation of the building. In line with the Toronto 2030 District goals, it is optimal for this system to be electric rather than fossil fuel dependent, in order to achieve a solution that entirely avoids GHG emissions. In reality, existing buildings generally operate using natural gas fuelled boilers, which might be integrated into the interventions applied in Bundle 1. The cost of this system is also non-trivial, and while it makes use of established technologies, there has yet to be widespread adoption within the Canadian context, which could limit adoption. With that in mind, the energy savings provided by Bundle 2 may be more readily adopted, as the interventions are less invasive and rely solely on electricity to operate. As Ontario currently generates its electricity at a low $\mathrm{CO}_{2} \mathrm{e} / \mathrm{kWh}$, implementing Bundle 2 may also provide a more beneficial impact overall in GHG emission reductions if a fossil-fuel fired auxiliary heating system were to be included with Bundle 1. Finally, Bundle 3: Moderate, achieved substantial reductions in energy use with minimally invasive interventions. While this bundle did not accomplish the increases in efficiency to the level observed in Bundles $1 \& 2$, it remains an attractive option for building owners looking to achieve simple yet effective solutions for reducing energy uses and associated GHG emissions. 


\subsection{Bundle Impacts on Total GHG Emissions at District Scale}

Table 10 presents the potential reduction of total GHG emissions if all office buildings in the district were to have the according bundles applied. This presents insight on how GHG emission reductions in the office building typology can impact the entire Toronto 2030 District. The amount of GHG emissions and percent reductions shown are based on the $2017 \mathrm{GHG}$ emission totals provided by the 2030 Platform website (2030 Districts, 2018).

Table 10 - Bundle Impacts on District GHG Emissions

\begin{tabular}{|l|c|c|c|c|c|c|}
\hline & $\begin{array}{c}\text { Electricity } \\
\text { GHG } \\
\text { Emissions } \\
\left(\mathbf{M t C O}_{\mathbf{2}} \mathbf{e}\right)\end{array}$ & $\begin{array}{c}\text { Natural } \\
\text { Gas GHG } \\
\text { Emissions } \\
\left(\mathbf{M t C O}_{\mathbf{2}} \mathbf{e}\right)\end{array}$ & $\begin{array}{c}\text { Resultant } \\
\mathbf{G H G} \\
\text { Emissions } \\
\left(\mathbf{M t C O}_{\mathbf{2}} \mathbf{e}\right)\end{array}$ & $\begin{array}{c}\text { Total GHG } \\
\text { Emissions } \\
\text { Saved } \\
\left(\mathbf{M t C O}_{\mathbf{2}} \mathbf{e}\right)\end{array}$ & $\begin{array}{c}\text { Reduction } \\
\text { in Office } \\
\text { Building } \\
\text { Emissions }\end{array}$ & $\begin{array}{c}\text { Reduction in } \\
\text { Total District } \\
\text { Emissions }\end{array}$ \\
\hline $\begin{array}{l}\text { Bundle 1: } \\
\text { Ambitious }\end{array}$ & 0.0285 & $\mathrm{~N} / \mathrm{A}$ & 0.0285 & 0.202 & $91.5 \%$ & $17.7 \%$ \\
\hline $\begin{array}{l}\text { Bundle 2: } \\
\text { High }\end{array}$ & 0.0310 & $\mathrm{~N} / \mathrm{A}$ & 0.0310 & 0.199 & $86.5 \%$ & $16.7 \%$ \\
\hline $\begin{array}{l}\text { Bundle 3: } \\
\text { Moderate }\end{array}$ & 0.0298 & 0.0890 & 0.119 & 0.111 & $48.3 \%$ & $9.3 \%$ \\
\hline
\end{tabular}

Each bundle was applied to the baseline model, and simulations provided the end use values for both the amount of electricity and natural gas use required for the operation of the building over a calendar year using the Toronto weather file. As EnergyPlus includes heating, cooling, and electrical loads, the various end uses were broken down into either electrical or natural gas values and converted into equivalent GHG emissions, respectively. Electricity use was converted using a value of $32 \mathrm{CO}_{2} \mathrm{e} / \mathrm{kWh}$, as used in the Toronto 2030 Platform, provided by Toronto Hydro for 2017 (Canadian Urban Institute, 2017). Natural gas use was converted using a value of 1874.6 grams $\mathrm{CO}_{2} \mathrm{e} / \mathrm{m}^{3}$, also consistent with the Toronto 2030 Platform, provided by Enbridge Inc. (Canadian Urban Institute, 2017). The effects of each bundle on the baseline end uses were then converted into a GHGI for each bundle, in units of $\mathrm{gCO}_{2} \mathrm{e} / \mathrm{m}^{2}$ and extrapolated across the 
district using the gross office floor area of $8,671,000 \mathrm{~m}^{2}$ (Canadian Urban Institute, 2017). After each bundle's GHGI was extrapolated for all office buildings, the total equivalent megatons of carbon dioxide $\left(\mathrm{MtCO}_{2} \mathrm{e}\right)$ were determined for the year. This hypothetical value for the simulated total GHG emissions for one year, post-intervention was then compared to the historical baseline, as quoted by the Toronto 2030 platforms amount of GHG emissions from all offices in the district for the year of 2017. The total emissions attributed to both electricity use, and natural gas uses are broken down for each bundle. Bundle 1 was able to achieve an estimated $91.5 \%$ reduction in GHG emissions, which included no emissions due to natural gas use, as all natural gas was assumed to have been eliminated through the inclusion of the GSHP and solar thermal systems, which are anticipated to achieve heating demands required for the winter months. Likewise, Bundle 2 was able to operate without the any GHG emissions related to the burning of fossil fuels, as the entire HVAC system utilizes electricity as an energy source. Bundle 2 achieved an $86.5 \%$ reduction in the total GHG emissions, where all associated emissions were related to electricity drawn from Ontario's electrical grid. Bundle 3 was able to reduce GHG emissions by $48.3 \%$, including both emissions related to electricity, and natural gas burned by the boiler. While Bundle 3's impacts were dominated by the GHG emissions related to natural gas uses, there were still significant reductions observed in the amount of electricity related GHG emission that made the "Moderate" scenario still an attractive option for achieving the Toronto 2030 District goals.

\subsection{Recommend Course of Action}

The recommendation for existing office building owners is to implement Bundle 1 in order to most aggressively work towards achieving 2030 District goals and overarching global climate change mitigation initiatives. In this scenario, Bundle 1 would be applied to all buildings, 
optimally with connection to the existing Enwave district heating system for auxiliary heating during extreme weather. As Toronto's 2030 District initiative aims to reduce GHG emissions by $50 \%$ by 2030 , if Bundle 1 were to be implemented on offices over the next twelve years, the remaining building typologies would also be required to make an overall $33.1 \%$ reduction in their GHG emissions in order to reach the intended goal.

In this course of action, we assume Bundle 1 uses an electrical auxiliary heating device for supplemental heating demands. In this scenario, Bundle 1 would provide the best of both worlds, with options to tie into district heating networks, while also using clean grid electricity for powering the boiler, and terminal WSHP units. Bundle 1 also includes the use of rooftop solar thermal panels, which can provide heating during the winter months for the cost of seasonal thermal storage. Contrarily, the VRF based Bundle 2 may be more valuable where solar thermal energy is not possible due to shading effects experienced from adjacent buildings. Considering this, either Bundle 1 or 2 are both beneficial options, but may depend on the site specific details related to location and availability of connections to the district heating network, as well as shading concerns related to solar thermal capture. Such concerns must be addressed on a case by case basis for each office building, if the interventions are to be investigated for their plausibility.

In a more pragmatic scenario, it is recommended that building owners consider the feasibility of the LED intervention, as was included in Bundle 3. This intervention presents a first step towards reducing their carbon footprint, which could be embraced by a large volume of office buildings in the district. Performing an LED relamping is a simple yet highly effective solution, which provides a large reduction on the electricity loads in a building, with some associated GHG emission reductions, particularly during peak times when natural gas-fired plants are used to top up the electricity grid, if aggregated over the entire building stock. As a stand-alone, this 
intervention is minimally invasive, and can be applied more easily than the described HVAC system overhauls required in Bundles 1 \& 2, while still creating major reductions in the GHG emissions attributed to office buildings. In addition to LED relamping, recent research has shown that optimized controls strategies can readily achieve $25-50 \%$ energy savings for heating and cooling systems, resulting in significant GHG emissions reductions with minimal cost . 


\section{Discussion}

\subsection{Error Discussion}

This section highlights the limitations of the study and assumptions made that had influence on the accuracy of the results.

\subsubsection{Use of a Single Typology}

It should be noted that only the "Large Office" typology was used in simulation, rather than the exact breakdown of office building heights present in the district. This was necessary as the data available during this MRP did not permit sub-classification of offices as large, medium, or small. That said, given the density of Toronto, the large typology (12 storey DOE model) is believed to be a fair approximation for the average office height in the city, noting that while several midrise offices are also present within the district, they are balanced by the presence of much taller towers. This use of a median building to represent the whole, while non-ideal, is consistent with other urban building energy modeling work (Cerezo Davila, et al., 2016) and was deemed fair for use in the Toronto 2030 Platform.

\subsubsection{Baseline Model Calibration}

Most significantly, the baseline reference file was unable to be calibrated against actual utility data of a prototypical Toronto office building, therefore any error in the initial baseline model's accuracy is magnified when results are extrapolated across the district. As well, the total amount of reductions achieved district wide were considered when applied to the baseline model, which was not validated against the Toronto 2030 Platform district totals. This could have been remedied through adjusting the baseline model's EUI and GHG emissions to represent the average value for the "Office" building typology data utilized in the Toronto 2030 Platform. 
Further to this, when comparing each bundle's simulated total district energy use and GHG emissions to actual data provided by the Toronto 2030 District Platform, simulated results are disproportionate, as they present findings specific to a "Large Office" reference building, where as 2030 Platform data is comprised of data for all sizes of office buildings.

Regarding the baseline model's material composition, there may have been opportunity to investigate DOE model's from other cities (e.g. Boston, New York) which more accurately represent Toronto's building stock. The baseline model selection was solely based on matching Toronto's climate zone, when in reality there may be differences in material selection due to influences beyond climate zone alone.

\subsubsection{Simulations}

GSHP intervention simulations were not performed beyond a year to ensure that a long-term heat balance was maintained, nor was a typical soil thermal conductivity for Toronto verified and applied to the model. Furthermore, the installation of multiple interventions at once may not serve as an accurate representation of the buildings immediate response to the upgrades. It is assumed that managing the fluid operation of all interventions likely requires fine-tuning by building owners to ensure each system works in sync with another, and to the demands of the occupants. As well, the interventions are presumed to have produced the intended effect as exactly specified by simulations, when in reality the potential for error in installation phase is always possible, where implemented changes may not achieve expectations. This can be considered as an inherent error applicable to all building energy model simulations, emphasizing the need for post-occupancy performance evaluations, to ensure interventions meet the anticipated goals set forth. 


\subsection{Results}

Overall, the level of energy use and GHG emission reductions were surprising, as a high degree of savings were achieved in the simulations. Particularly, the singular impact of the solar intervention was unexpected, as generally these collectors are considered to be less effective in Toronto's climate. This may present and opportunity for further investigation into the viability of solar thermal collectors in cold climates, as they can provide substantial reductions in natural gas end uses and consequent GHG emissions. Conversely, the simulations of the ERV intervention provided results which were less impactful than what was anticipated. This highlights another reason why cost should integrated into future studies, as the ERV may not achieve cost effective results. Further to this, there could have been more emphasis placed on determining the optimal number of interventions at once, as the diminished impact of each additional intervention may not be cost effective.

\subsection{Carbon - Total Energy trade-off}

In some scenarios, ECMs were able to achieve a decrease in the total energy use but resulted in an overall increase in $\mathrm{CO}_{2}$ emissions, contrary to 2030 District goals. An example of this was observed in the LED relamping ECM, where the interior lighting and total energy load decreased despite an increased heating load. As the baseline model's heating load is managed through the burning of natural gas, the ECM's impact will have resulted in an overall increase in net $\mathrm{CO}_{2}$ emissions. In scenarios such as this, building owners must take into consideration the goal each intervention hopes to achieve, whether it be an emphasis on reducing operating costs or $\mathrm{CO}_{2}$ emissions. Additionally, when considering cost implications, it is important to consider the cost of both natural gas and electricity per energy output. Currently, the Ontario commercial natural 
gas rate is approximately $2.5 \phi / \mathrm{kWh}$, roughly one quarter the price of electricity, at $9.4 \phi / \mathrm{kWh}$ for mid-peak hours (Enbridge, 2018). Due to this, building owners may be dissuaded from investing in an HVAC system powered by electricity as operating costs are increased, barring the future impact of Canada's federal carbon tax policy, which is addressed in the following section.

\subsection{Financing}

A great deal of further investigation is required to determine the cost of each intervention, and what potential savings beyond utility cost can be realized from their implementation. This aspect was not considered in the study, yet it is the main concern of building owners when considering plausibility. A more realistic way to determine the recommend course of action would involve combining costing into the results, in order find the most cost optimal avenues to energy reductions, which provide financially desirable outcomes for building owners. In extension of this, Canada's current federal carbon taxation plan will likely have an influence on the future of how buildings are constructed with regard to both envelope designs and HVAC system selections, as the pollution pricing system continues to roll out over the following years (Government of Canada, 2019). Included in the new fuel charge rates applied to Ontario is an additional \$20 per tonne of carbon dioxide equivalent $\left(\mathrm{CO}_{2} \mathrm{e}\right)$ in 2019 , which will be increasing incrementally by year to a $\$ 50$ charge per tonne of $\mathrm{CO}_{2} \mathrm{e}$ in 2022 (Department of Finance Canada, 2018). When converted into fuel charge rates per unit of 'marketable natural gas', the carbon tax will equate to an additional charge of $\$ 0.0391$ per every cubic meter of natural gas, increasing to $\$ 0.0979$ per cubic meter of natural gas used in 2022 (Department of Finance Canada, 2018). Given this scenario, it is expected that current and future owners of large buildings which require a massive volume of natural gas to reach their heating demands during winter months will begin to more strongly consider what alternative heating options exist for 
buildings operating under Toronto's climate. In this situation it is expected that the 'invisible hand of the market' will dictate that building owners will then see the benefit to switching their heating systems to which do not rely on natural gas, and operate in a more carbon neutral manner (e.g. VRF, GSHP, Solar Thermal systems) in order to avoid potential fees incurred by natural gas use, per the federal fuel charge rates. Furthermore, as pollution pricing across Canada becomes more aggressive in the following years, there is hope to stimulate innovations and investments in building technologies that operate in a more carbon neutral manner. If these building HVAC technologies are more heavily invested in, prices may be driven down to levels that may be more financially optimal for building owners. Under this framework, the retrofit solutions described in this study may become more economically feasible, when compared to the existing natural gas fueled HVAC technologies that are currently contained in majority of high-rise office towers across Toronto’s 2030 District.

\subsection{Additional Building Typologies}

Similar investigations to evaluate the potential of ambitious, high, and moderate bundles to complement those proposed for offices in the remaining building typologies in the district would provide great value. First, these would provide a better context to the results found in this study and present a roadmap for energy and GHG reduction in the Toronto 2030 district. While the Office typology was found to be the largest contributors to GHG emissions and energy uses, and therefore this study represents the highest impact scenario of savings, other typologies such as "Multi-Unit Residential” and "Retail \& Hospitality" (34.1\%, and17.6\% of district floorspace, respectively) are also significant and a comprehensive approach incorporating these elements is necessary to complete the picture (2030 Districts, 2018). 


\subsection{Implications}

In order properly manage the environmental costs our buildings impose, it is crucial to quantify our current impact, and determine the necessary adjustments to achieve a sustainable approach to living. As Canada exists as a nation with the economic and technological resources available to make adjustments to operating a more sustainable built environment, it is important that we examine the opportunities available through research, as such has been described in this study. By outlining concrete solutions to adapting our built environment, we become better equipped to make definitive improvements to reduce the GHG emissions of our existing infrastructure and buildings. This will assist Canada to reach the goals set forth by such agencies as the Intergovernmental Panel on Climate Change (IPCC, 2014). This research contributes to these goals by quantifying the potential benefits of building retrofits to reduce the volume of carbon emitted into our atmosphere and provide a roadmap to 2030. As Canada's urban metropolises continue to expand, it is important that we ensure this growth occurs in an efficient manner. As such, it is essential that Canada is able to set a precedent for the standards of efficiency our buildings have and present a roadmap to substantial GHG reductions that could be replicated for different regions. In this regard, we can hope to influence other regions outside of the Toronto 2030 District who are currently experiencing population growth and subsequent urbanization, to become early adopters of climate change mitigation. As the research presented here suggests, if the Ambitious or High bundles were applied to all offices across Toronto, Ontario, and all of Canada, there is potential to significantly reduce GHG emissions. In extension of this, the interventions included in Bundle 1 and 2 are broadly applicable to most existing building typologies, therefore we could possibly make even further reductions in the GHG emissions attributed to building uses across all typologies. Based on end use data collected from the 2012 
Commercial Buildings Energy Consumption Survey (CBECS), commercial building energy end uses are largely dominated by their space heating requirements (EIA, 2016). As Bundle 1 and 2 provide key HVAC interventions that directly target these extensive energy uses, their application is highly valuable to making the large reductions in energy use experienced by both office buildings and other energy dominant typologies for the North American context.

To evaluate potential GHG reductions at the national scale, data from the 2014 Survey of Commercial and Institutional Energy Use in Canada was considered. This data revealed that the commercial and institutional building typologies in Ontario accounted for $35.6 \%$ of the floor space of these building typologies in Canada (Statistics Canada, 2016), showing that Ontario, and specifically Toronto, which includes a large portion of urbanized area, contain a large stock of buildings that are strong candidates for the retrofits outlined in this MRP. Furthermore, these results confirm that these building typologies (i.e. commercial and institutional) consumed the highest share of energy in Canada, at $41.6 \%$ of the total energy use attributed to building operations in Canada (Statistics Canada, 2016). As the bundles produced in this study are broadly applicable to both commercial and institutional building typologies in Canada, there is a large potential for energy savings and GHG emissions, if applied nationally. 


\section{Conclusions}

Simulated results were successful in providing an approximate impact each intervention had on the baseline file. As expected, the interventions were able to achieve energy use and GHG emission reductions at varying levels of effectiveness, depending on the nature of the intervention. It was also found that combining an increasing number of interventions provided diminishing amounts of reductions, to levels which may not become cost effective. With the data presented, it appears unlikely that building owners would feel incentivized enough to complete multiple building interventions at once, as there were highly diminished returns on energy savings observed with each additional intervention. Given these results, it appears that implementing two major building interventions provide the most significant reductions in energy use and consequent GHG emissions, in line with Toronto 2030 District initiatives. As well, if building owners are to consider these interventions practical enough, they may be needed to be performed at a point where HVAC system upgrades are already required, due to aging equipment.

Specific to the bundle creation, it was determined that there is a potential to achieve a $91.7 \%$ reduction in GHG emissions, when implementing Bundle 3 on all office buildings across the district. If we are to apply the reduction in emissions observed for large office buildings, as part of their impact on the entire district emissions, the Bundle 3's impact equates to a $17.7 \%$ reduction in the total GHG emissions. This bundle included the conversion of an HVAC system originally ran on fossil fuels, to one relying on a combination of solar thermal heat, ground source heat pumps, electrically driven water source heat pumps, and LED lighting. It was able to provide substantial reductions in GHG emissions, and proves to be the most constructive option for reaching Toronto 2030 District goals. Limitations 


\subsection{Limitations}

A key limitation of this study was its narrow scope. As the research was solely focused on the large office DOE baseline model, it provided simulation results specific to one building typology. Considering the entire Toronto 2030 District, this study is limited to the application of interventions on one type of building, when in reality there are numerous other typologies present within the building stock. Furthermore, the simulation of interventions is limited to the accuracy of the original building energy model, and the climate file used for generating weather data specific to Toronto. There are inherent limitations to the accuracy of building energy models which may reduce the reliability of these results, as compared to how their impactful they are in reality. As well, there were some assumptions used in the solar thermal intervention, namely the $50 \%$ coverage of the rooftop area and an absence of shading from adjacent structures that may limit the accuracy and applicability of results.

\subsection{Further Work}

Further studies in this area are recommended to provide a more nuanced depiction of current building energy uses in the urban landscape, ensuring we are better equipped for making the transition to an infrastructure grid that includes more renewable resource systems that are integrated into the district scale. Research into electricity storage, smart grids, and their integration with electrically driven HVAC systems requires more analysis. Additionally, more research may be needed on how solar thermal collectors could be integrated into large buildings in the Toronto context. While large office buildings appear to be cooling dominant over the aggregate of the year, their heating load is substantial during the winter months. In this regard, there may be a potential for heavily reducing the heating demand in buildings that currently 
utilize natural gas furnaces, through offsets achieved by rooftop solar thermal collector panels. Through combining solar thermal technologies into existing large building HVAC systems, there may be substantial carbon emission reduction opportunities, but more research is required into both their feasibility of implementation, and performance in cold climates such as observed in Toronto. Additionally, more investigation into how HVAC systems described in this study (e.g. GSHP, WSHP) can be integrated into Toronto's existing district heating network is required to ensure this resource is leveraged efficiently. 


\section{References}

2030 Districts, 2018. 2030 Districts Project Portal| High Performance Building Districts.

[Online]

Available at: http://www.2030districts.org/toronto

Aagard, T. \& O'Hearn, K., 2017. Evolution of Ontario's Incentivized Energy Manager

Programs. Denver, American Council for an Energy-Efficient Economy, pp. 3.1-3.12.

Ahmad, M. \& Culp, C. H., 20016. Uncalibrated building energy simulation modeling results. HVAC\&R Research, Volume 12.4, pp. 1141-1155.

Akbari, H. et al., 1994. A New Approach to Estimate Commercial Sector End-Use Load Shapes and Energy Use Intensities, Berkely: Lawrence Berkeley Laboratory.

Akbari, H., Eto, J. \& Turiel, I., 1989. Integrated Estimation of Commercial Sector End-Use Load Shapes and Energy Use Intensities, Berkeley: Lawerence Berkeley Laboratory.

Al-Mumin, A., Khattab, O. \& Sridhar, G., 2003. Occupants' Behaviour and Activity Patterns Influencing the Energy Consumption in the Kuwaiti Residences. Energy and Buildings, 35(6), pp. 549-559.

Amara, F. et al., 2015. Comparison and Simulation of Building Thermal Models for Effective Energy Management. Smart Grid and Renewable Energy, pp. 95-112.

Andrews, R. \& Johnson, E., 2016. Energy Use, Behavioural Change, and Business

Organizations: Reviewing Recent Findings and Proposing a Future Research Agenda. Energy Research and Social Science, Volume 11, pp. 195-208. 
ASHRAE, 2013. Standard 90.1-2013, Energy Standard for Buildings except Low-rise

Residential Buildings. Atlanta: American Society of Heating, Refrigerating, and Air-

Conditioning Engineers.

Bach, B. W. J. O. T. M. M. M. J. M. \&. E. B., 2016. Integration of large-scale heat pumps in the district heating systems of Greater Copenhagen. Energy, Volume 107, pp. 321-334.

Ballarini, I., Corgnati, S. \& Corrado, V., 2014. Use of reference buildings to assess the energy saving potentials of the residential building stock: The experience of TABULA project. Energy Policy, Volume 68, pp. 273-284.

Ballarini, I., Corgnati, S. P., Corrado, V. \& Tala, N., 2011. Improving Energy Modeling of Large Building Stock Through the Development of Archetype Buildings. Sidney, s.n.

Bettelle Pacific Northwest Laboratory, 1983. Recommendations for Energy Conservation Standards and Guidelines for New Commercial Buildings, Richland: Betelle Pacific Northwest Laboratory.

Bozorgi, A., 2015. Integrating Value and Uncertainty in the Energy Retrofit Analysis in Real Estate Investment - Next Generation of Energy Efficiency Assessment Tools. Energy Efficiency, Volume 8, pp. 1015-1034.

Brown, R. E. et al., 2014. Getting real with energy data: Using the buildings performance database to support data-driven analyses and decision-making. s.1., s.n.

Buildings Performance Institute Europe, 2011. Europe's Buildings Under the Microscope: A country-by-country review of the energy performance of buildings, s.l.: s.n. 
Cagno, E., Trianni, A., Worrell, E. \& Miggiano, F., 2014. Barriersd and Drivers for Energy Efficiency: Different Perspectives from an Exploratory Study in the Netherlands. Energy Procedia, pp. 1256-1260.

Cajias, M. \& Piazolo, D., 2013. Green performs better: energy efficiency and financial return on buildings. Journal of Corporate Real Estate, 15(1), pp. 53-72.

Canadian Energy Issues, 2016. Ontario power stats. [Online]

Available at: http://canadianenergyissues.com/ontario-power-stats/

Canadian Urban Institute, 2017. Toronto 2030 Platform - Data Catalogue. [Online]

Available at: https://www.toronto2030platform.ca/data-and-definitions

[Accessed 29 April 2019].

Castleberry, B., Gliedt, T. \& Greene, J., 2016. Assessing Drivers and Barriers of Energy-saving Measures in Oklahoma's Public Schools. Energy Policy, Volume 88, pp. 216-228.

Cerezo Davila, C., Reinhart, C. \& Bemis, J., 2016. Modeling Boston: A Workflow for the Generation of Complete Urban Building Energy Demand Models from Existing Urban Geospatial Data. Energy, Volume 117, pp. 237-250.

Cerezo, C., Sokol, J., Reinhart, C. \& Al-Mumin, A., 2015. Three Methods for Characterizing Building Archetypes in Urban Energy Simulation. Hyderabad, s.n.

Cheng, J. C. \& Das, M., 2014. A BIM-based web service framework for green building energy simulation and code checking. Journal of INformation Technology in Construction (ITcon), Volume 19, pp. 150-168. 
Chen, Y., Hong, T. \& Piette, M. A., 2017. Automatic generation and simulation of urban building energy models based on city datasets for city-scale building retrofit analysis. , 205(July), 323-335.. Applied Energy, Volume 205, pp. 323-335.

Chen, Y., Hong, T., Piette, M. A. \& Berkeley, L., 2017. City-Scale Building Retrofit Analysis : A Case Study using CityBES Abstract CityBES. Proc. Building Simulation 2017, Issue August, pp. 1084-1091.

Chen, Y., Tan, H. \& Berardi, U., 2017. Day-ahead Prediction of Hourly Electric Demand in Non-Stationary. Energy and Buildings, Volume 148, pp. 228-237.

City of Toronto, 2017. Zero Emissions Building Framework. p. 118.

Coakley, D. R. P. \&. K. M., 2014. A review of methods to match building energy simulation models to measured data. Renewable and sustainable energy reviews, Volume 37, pp. 123-141.

Coates, P., Arayici, Y. \& Ozturk, Z., 2012. New Concepts of Post Occupancy Evaluation (POE) Utilizing BIM Benchmarking Techniques and Sensing Devices. Marseilles, France, SpringerVerlag, pp. 319-329.

Copiello, S., 2017. Building Energy Efficiency: A Research Branch made of Paradoxes. Renewable and Sustainable Energy Reviews, Volume 69, pp. 1064-1076.

Corgnati, S., Fabriztio, E., Filippi, M. \& Monetti, V., 2013. Reference buildings for cost optimal analysis: Method of definition and application. Applied Energy, Volume 102, pp. 983-993.

Crawley, D. B., Hand, J. W., Kummert, M. \& Griffith, B. T., 2008. Contrasting the capabilities of building energy performance simulation programs. Building and Environment, April, 43(4), pp. 661-673. 
Crawley, D. L. L. W. F. B. W. H. Y. P. C. S. R. L. R. F. D. W. M. a. G. J., 2001. EnergyPlus: creating a new-generation building. Energy and Buildings, Volume 33, pp. 319-331.

De Wilde, P., 2014. The gap between predicted and measured energy performance of buildings: a framework for investigation. Automation in Construction, Volume 41, pp. 40-49.

De Wilde, P., 2014. The gap between predicted and measured energy performance of buildings: A framework for investigation. Automation in Construction, Volume 41, pp. 40-49.

Department of Energy, 2015. EnergyPlus Input Output Encyclopedic Reference. s.1.:s.n.

Department of Finance Canada, 2018. Fuel Charge Rates in Listed Provinces and Territories (Carbon Pollution Price). [Online]

Available at: https://www.fin.gc.ca/n18/data/18-097_1-eng.asp

[Accessed 26 April 2019].

Deru, M., Crawley, D. \& Halverson, M., 2008. DOE Commercial Building Benchmark Models. Pacific Grove, s.n.

Deru, M. et al., 2011. U.S. Department of Energy commercial reference building models of the national building stock, s.1.: s.n.

Difs, K. B. M. T. L. \&. N. L., 2010. Energy conservation measures in buildings heated by district heating-a local energy system perspective.. Energy, Volume 35, pp. 3194-3203.

Difs, K. B. M. T. L. \&. N. L., n.d. Difs, Kristina, et al. "Energy conservation measures in buildings heated by district heating-a local energy system perspective.

Dobson, L., 2018. Summary of Total Electricity Use by Building Type. Toronto: s.n. 
DOE, 2016. eQUEST: the QUick Energy Simulation Tool. [Online]

Available at: http://www.doe2.com/equest/

EIA, 2016. 2012 Commercial Buildings Energy Consumption Survey: Energy Usage Summary, Washington, D.C.: U.S. Energy Information Administration.

El Asmi, E., Robert, S., Haas, B. \& Zreik, K., 2015. A standardized approach to BIM and energy simulation connection. International Journal of Design Sciences and Technology, 21(1), pp. 5982.

Enbridge, 2017. GHG Emissions Forecasts - Enbridge Gas. [Online]

Available at: http://www.enbridge.com/sustainability-reports/sustainability-report/priorityareas/renewable-and-low-carbon-energy/climate-change-emissions-reduction-and-energyefficiency

[Accessed 20 December 2018].

Enbridge, 2018. Natural Gas Commercial and Industrial Rates. [Online]

Available at: $\underline{\text { https://www.enbridgegas.com/Understanding-gas-rates }}$

[Accessed 12 December 2018].

Energy Information Administration, 1991. Commercial Building Characteristics 1989,

Washington: U.S. Department of Energy.

Energy Information Administration, 2006. 2003 Commercial Building Energy Consumption Survey, Washington: EIA.

Famuyibo, A. A., Duffy, Aidan \& Strachan, P., 2012. Developing Archetypes for Domestic Dwellings - An Irish Case Study. Energy and Buildings, Volume 50, pp. 150-157. 
Fan, C., Xiao, F. \& Wang, S., 2014. Development of prediction models for next-day building energy consumption and peak power demand using data mining techniques. Applied Energy, Volume 127, pp. 1-10.

Fan, C., Xiao, F. \& Zhao, Y., 2017. A short-term building cooling load prediction method using deep learning algorithms. Applied Energy, Volume 195, pp. 222-233.

Fuerst, F., 2009. Building momentum: An analysis of investment trends in LEED and Energy Star-certified properties.. J Retail Leisure Property, 8(4), pp. 285-297.

Gliedt, A. \& Hoicka, C., 2015. Energy Upgrades as Financial and Strategic Investment?: Energy Star Property Owners and Managers Improving Building Performance. Applied Energy, Volume 147, pp. 430-443.

Government of Canada, 2019. Ontario and Pollution Pricing. [Online]

Available at: https://www.canada.ca/en/environment-climate-change/services/climate-

change/pricing-pollution-how-it-will-work/ontario.html

[Accessed 26 April 2019].

Government of Ontario, 2011. O. Reg. 397/11: ENERGY CONSERVATION AND DEMAND

MANAGEMENT PLANS. [Online]

Available at: https://www.ontario.ca/laws/regulation/r11397

[Accessed 22 November 2017].

Government of Ontario, 2011. O. REG. 397/11: ENERGY CONSERVATION AND DEMAND

MANAGEMENT PLANS. [Online]

Available at: https://www.ontario.ca/laws/regulation/r11397

[Accessed 16 November 2017]. 
Government of Ontario, 2019. Environment and Energy: End of Coal. [Online]

Available at: https://www.ontario.ca/page/end-coal

[Accessed 28 April 2019].

Griffith, B., Torcellini, P. \& Long, N., 2006. Assesment of the Technical Potential for Achieving Zero-Energy Commercial Buildings. Pacific Grove, s.n.

Gupta, R. \& Gregg, M., 2018. Targeting and modelling urban energy retrofits using a city-scale energy mapping approach. Journal of Cleaner Production, Volume 174, pp. 401-412.

Ham, Y. \& Golparvar-Fard, M., 2015. Mapping actual thermal properties to building elements in gbXML-based BIM for reliable building energy performance modeling. Automation in Construction, 49(Part B), pp. 214-224.

Harb, H. et al., 2016. Development and validation of grey-box models for forecasting the thermal responce of occupied buildings. Energy and Buildings, pp. 199-207.

Hraska, J., 2015. Chronobiological aspects of green buildings daylighting.. Renewable Energy, Volume 73, pp. 109-114.

Huang, H., Chen, L., Hu \& E., 2015b. A neural network-based multi-zone modelling approach for predictive control system design in commercial buildings. Energy and Buildings, Volume 97 , pp. 86-97.

Huang, H., Chen, L. \& Hu, E., 2015. A new model predictive control scheme for energy and cost savings in commercial buildings: An aairport terminal building case study. Building and Environment, pp. 203-216. 
Ianni, M. \& de León, M. S., 2013. Applying Energy Performance-Based Design in Early Design Stages. 18, p.31.. Delft, s.n., pp. 31-40.

IESO, 2017. Climate Change: Conservation and Framework Mid-Term Review.

International Energy Agency, 2015. World Energy Outlook 2015, Paris: International Energy Agency.

IPCC, 2014. Climate Change 2014 - Mitigation of Climate Change, New York: Cambridge University Press - Intergovernmental Panel on Climate Change.

Kim, J. B. et al., 2015. Developing a physical BIM library for building thermal energy simulation. Automation in Construction, 50(2015), pp. 16-28.

Kim, Y. S. H. M. D. M. \&. S. J., 2017. Building energy model calibration with schedules derived from electricity use data.. Applied Energy, Volume 190, pp. 997-1007.

Kivimaa, P. \& Martiskainen, M., 2018. Innovation, Low Energy Buildings and Intermediaries in Europe: Systemic Case Study Review. Energy Efficiency, Volume 11, pp. 31-51.

Kok, N., McGraw, M. \& Quigley, J., 2011. The Diffusion of Energy Efficiency in Building. s.l., s.n., p. 7.

Liu, X. \&. H. G., 2006. Enhancements of an integrated simulation tool for ground-source heat pump system design and energy analysis. Proceedings of Ecostock.

Li, X. \& Wen, J., 2014. Review of building energy modeling for control and operation. Renewable and Sustainable Energy Reviews, pp. 517-537.

Lokmanhekim, M. et al., 1979. DOE-2: a new state-of-the-art computer program for the energy utilization analysis of buildings, Berkeley, California: Lawrence Berkeley Laboratory. 
Lundström, L. \&. W. F., 2016. Heat demand profiles of energy conservation measures in buildings and their impact on a district heating system. Applied Energy, Volume 161, pp. 290299.

Ma, J., Qin, J., Salsbury, T. \& Xu, P., 2012. Demand reduction in building energy systems based on economic model predictive control. Chemical Engineering Science, pp. 92-100.

Manso, M. \& Castro-Gomes, J., 2015. Green wall systems: A review of their characteristics.. Renewable and Sustainable Energy Reviews, Volume 41, pp. 863-871.

McArthur, J. S. X., 2017. Disrupting the Status Quo with Early-Stage BIM-Based Energy Modeling. Technology, Architecture, and Design (TAD) Journal, 1(2), pp. 231-239.

Mendieta, C. X., 2018. A Comparison of Bottom-Up Methods for Estimating Institutional Building Energy Use to Inform Resource and Emission Reduction Strategies. Toronto: Ryerson University (MASc. Thesis).

Mendieta, X., 2018. A Comparison of Bottom-Up Methods for Estimating Institutional Building Energy Use to Inform Resource and Emission Reduction Strategies, Toronto: Ryerson University.

Menezes, C., Cripps, A., Bouchlaghem, D. \& Buswell, R., 2012. Predicted vs. actual energy performance of non-domestic buildings: using post-occupancy evaluation data to reduce the performance gap. Applied Energy, Volume 97, pp. 335-364.

Mocanu, E. M. D. et al., 2018. On-line building energy optimization using deep reinforcement learning. IEEE Transactions on Smart Grid. 
Molina-Solana, M. et al., 2017. Data science for building energy management: A review. Renewable and Sustainable Energy Reviews, Volume 70, pp. 598-609.

Mostafavi, N., Farzinmoghadam, M. \& Hoque, S., 2015. Envelope retrofit analysis using eQUEST, IESVE Revit Plug-in and Green Building Studio: a university dormitory case study. International Journal of Sustainable Energy, 34(9), pp. 594-613.

Murugappan, A., 2002. Implementing Ground Source Heat Pump and Ground Loop Heat Exchanger Models in the EnergyPlus Simulation Environment. Oklahoma State University M.S. Thesis.

Mustafaraj, G., Lowry, G. \& J.Chen, 2011. Prediction of room temperature and relative humidity by autoregressive linear and nonlinear neural network models for an open office. Energy and Buildings, pp. 1452-1460.

Natarajan, M. et al., 2015. Living wall systems: evaluating life-cycle energy, water and carbon impacts.. Urban Ecosystems, 18(1), pp. 1-11.

National Resources Canada, 2017. Major Energy Retrofit Guidelines for Commercial and Institutional Buildings, s.1.: Natural Resources Canada's Office of Energy Efficiency. NRCan, 2009. Survey of Commercial and Institutional Energy Use (SCIEU), Ottawa: Government of Canada (Natural Resources Canada).

NRCan, 2012. ENERGY STAR® in Canada Annual Report 2011-2012, Ottawa: Natural Resources Canada.

NRCan, 2014. ENERGY STAR® in Canada Annual Report 2014, Ottawa: Natural Resources Canada. 
NREL, 2016. Downloads. [Online]

Available at: https://energyplus.net/downloads

Numerical Logics, 1999. Canadian Weather for Energy Calculations, Users Manual and CDROM. Downsview, Ontario: Environment Canada..

Oldewurtel, F. P. A. J. C. N. G. D. G. M. S. V. \&. M. M., 2012. Use of model predictive control and weather forecasts for energy efficient building climate control. Energy and Buildings,

Volume 45, pp. 15-27.

Ontario, 2009. Green Energy Act, 2009. [Online]

Available at: https://www.ontario.ca/laws/statute/09g12?search=e+laws

[Accessed 120720 18].

Østergård, T., Jensen, R. \& and Maagaard, S., 2016. Building simulations supporting decision making in early design-A review. Renewable and Sustainable Energy Reviews, Volume 61, pp. $187-201$.

Paudel, S. E. M. et al., 2017. A relevant data selection method for energy consumption prediction of low energy building based on support vector machine. Energy and Buildings, Volume 138, pp. $240-256$.

Penman, J. M., 2000. A Database and Model of Energy Use in Nondomestic Building Stock of England and Wales. London, s.n.

Perez-Lombard, L., Ortiz, J., Gonzalez, R. \& Maestre, I. R., 2008. A review of benchmarking, rating and labelling concepts within the framework of building energy certification schemes. Energy and Buildings, Volume 41, pp. 272-278. 
Persson, J. \& Gronkvist, S., 2015. Drivers for and Barriers to low-energy Buildings in Sweden. Journal of Cleaner Production, Volume 109, pp. 296-304.

Picco, M., Lollini, R. \& Marengo, M., 2014. Towards energy performance evaluation in early stage building design: A simplification methodology for commercial building models. Energy and Buildings, Volume 76, pp. 497-505.

Porse, E. et al., 2016. Structural, geographic, and social factors in urban building energy use: Analysis of aggregated account-level consumption data in a megacity. Energy Policy, Volume 96, pp. 179-192.

Qiu, Y., Tiwari, A. \& Wang, Y., 2015. The diffusion of voluntary green building certification: a spatial approach.. Energy Efficiency, 8(3), pp. 449-471.

Raustad, R., 2013. A variable refrigerant flow heat pump computer model in EnergyPlus. ASHRAE Transaction.

REALPac, 2013. 2012 Energy Benchmarking Report Performance of the Canadian Office Sector, Toronto: s.n.

Reinhart, C. F. \& Cerezo Davila, C., 2015. Urban Building Energy Modeling - A Review of a Nascent Field. Buildings and Environment, Volume 97, pp. 196-202.

Reinhart, C. F. \& Cerezo Davila, C., 2016. Urban building energy modeling - A review of a nascent field. Building and Environment, 15 2, Volume 97, pp. 196-202.

Samuelson, H. W., Ghorayshi, A. \& Reinhart, C. F., 2016. Analysis of a simplified calibration procedure for 18 design-phase building energy models. Journal of Building Performance Simulation, Volume 9.1, pp. 17-29. 
Seryak, K. \& Kissock, K., 2003. Occupancy and Behavioral Affects on Residential Energy Use. Austin, s.n.

Siddharth, V. R. P. V. G. T. \&. S. A., 2011. Automatic generation of energy conservation measures in buildings using genetic algorithms.. Energy and Buildings, 43(10), pp. 2718-2726.

So, N. \& Richman, R., 2016. A High Level Method to Disaggregate Electricity for ClusterMetered Buildings. Energy and Buildings, Volume 111, pp. 351-368.

Statistics Canada, 2016. Survey of Commercial and Institutional Energy Use, 2014. [Online] Available at: https://www150.statcan.gc.ca/n1/daily-quotidien/160916/dq160916c-eng.htm [Accessed 1 May 2019].

Stumpf, A., Kim, H. \& Jenicek, E., 2011. Early design energy analysis using building information modeling technology, s.l.: US Army Corps of Engineers Engineer Research and Development Center.

Sun, X., 2016. Investigating Building Information Model to Building Energy Model Data Transfer Integrity and Simulation Results [Thesis], Toronto: Ryerson University.

Swan, L. G. \& Ugursal, I. V., 2009. Modeling of End-Use Energy Consumption in the Residential Sector: A Review of Modeling Techniques. Renewable and Sustainable Energy Reviews, Volume 13, pp. 1819-1835.

Tamimi, B. C. C. \&. B. K., 2013. System stability impact of large-scale and distributed solar photovoltaic generation: The case of Ontario, Canada.. IEEE transactions on sustainable energy, 4(3), pp. 680-688. 
Tan, B. Y. Y. O. E. N. \&. Ç. E., 2016. Optimal selection of energy efficiency measures for energy sustainability of existing buildings.. Computers \& Operations Research, Volume 66, pp. $258-271$.

Tian, W. et al., 2017. Relationship between built form and energy performance of office buildings in a severe cold Chinese region. Building Simulation, 10(1), pp. 11-24.

Trane, 2018. Trane Water Source Heat Pump Axiom Water-to-Water. [Online] Available at: https://www.trane.com/commercial/north-america/us/en/productssystems/equipment/unitary/water-source-heat-pumps/water-to-water-wshp.html [Accessed 10 December 2018].

U.S. DOE, 2018. Snapshot - Linear Luminaires, Troffer Luminaires, \& Troffer Retrofit Kits, s.1.: DOE.

UNEP-SBCI, 2009. Common Carbon Metric for Measuring Energy Use \& Reporting Greenhouse Gas Emissions from Building Operations, Geneva: United Nations Energy Program - Sustainable Building and Climate Initiative.

Union Gas, 2018. Conversion Factors based on Energy Content. [Online] Available at: https://www.uniongas.com/business/save-money-and-energy/analyze-yourenergy/energy-insights-information/conversion-factors

USGSA, 2015. BIM guide 05 - Energy performance, s.1.: US General Services Administration.

Weger, H., 2018. Investigating the Effect of Changing Ratios and Flowrates on Photovoltaic Thermal and Evacuated Tube Collector Array Performance for Different Building Types, Toronto: Ryerson Universtiy. 
Wu, W., Yang, X. \& Fan, Q., 2014. GIS-BIM Based Virtual Facility Energy Assessment (VFEA)—Framework Development and Use Case of California State University, Fresno. Computing in Civil and Building Engineering, pp. 339-346.

Yan, D. et al., 2015. Occupant behavior modeling for building performance simulation: Current state and future challenges. Energy and Buildings, Volume 107, pp. 264-278.

Yavuzturk, C. \&. S. J. D., 1999. A short time step response factor model for vertical ground loop heat exchangers. Ashrae Transactions, Volume 105(2), pp. 475-485.

Zakeri, B. \&. S. S., 2015. Electrical energy storage systems: A comparative life cycle cost analysis. Renewable and Sustainable Energy Reviews, Volume 42, pp. 569-596. 


\section{Appendix A}

Table A.1 - Reference Building Exterior Material Thermal Properties

\begin{tabular}{|c|c|c|c|c|}
\hline Exterior Mass Wall & $\begin{array}{c}\text { Thermal } \\
\text { Conductivity, } \\
\mathbf{k}[\mathrm{W} / \mathrm{mK}]\end{array}$ & $\begin{array}{c}\text { Thickness } \\
\text { [m] }\end{array}$ & $\begin{array}{c}\text { U-Value } \\
{[\mathrm{W} / \mathbf{m} 2 \mathrm{~K}]}\end{array}$ & $\begin{array}{c}\text { Thermal } \\
\text { Resistance, } \\
\text { R [m2K/W] }\end{array}$ \\
\hline 1IN Stucco & 0.6918 & 0.0253 & 27.344 & 0.037 \\
\hline 8IN Concrete HW & 1.311 & 0.2032 & 6.452 & 0.155 \\
\hline Mass NonRes Wall Insulation & 0.049 & 0.10093 & 0.485 & 2.060 \\
\hline 1/2IN Gypsum & 0.16 & 0.0127 & 12.598 & 0.079 \\
\hline Total & & & & 2.33 \\
\hline Roof & $\begin{array}{c}\text { Thermal } \\
\text { Conductivity, } \\
\mathbf{k}[\mathrm{W} / \mathrm{mK}]\end{array}$ & $\begin{array}{c}\text { Thickness } \\
{[\mathrm{m}]}\end{array}$ & $\begin{array}{c}\text { U-Value } \\
{[\mathrm{W} / \mathrm{m} 2 \mathrm{~K}]}\end{array}$ & $\begin{array}{c}\text { Thermal } \\
\text { Resistance, } \\
\text { R [m2K/W] }\end{array}$ \\
\hline Roof Membrane & 0.16 & 0.0095 & 16.84 & 0.059 \\
\hline Non-Res Roof Insulation & 0.049 & 0.182 & 0.269 & 3.717 \\
\hline Metal Decking & 45.006 & 0.002 & 30004.000 & 0.000 \\
\hline Total & & & & 3.78 \\
\hline Slab & $\begin{array}{c}\text { Thermal } \\
\text { Conductivity, } \\
\mathbf{k}[\mathrm{W} / \mathrm{mK}]\end{array}$ & $\begin{array}{c}\text { Thickness } \\
{[\mathrm{m}]}\end{array}$ & $\begin{array}{c}\text { U-Value } \\
{[\mathrm{W} / \mathrm{m} 2 \mathrm{~K}]}\end{array}$ & $\begin{array}{c}\text { Thermal } \\
\text { Resistance, } \\
\text { R [m2K/W] }\end{array}$ \\
\hline HW Concrete & 1.311 & 0.1016 & 12.9035433 & 0.077498 \\
\hline Carpet & 0 & N/A & 0 & 0 \\
\hline Total & & & & $\mathbf{0 . 0 7 7}$ \\
\hline
\end{tabular}


Table A.2 - Evacuated Tube Solar Thermal Collector Properties (Wegner, 2018)

\begin{tabular}{|c|c|c|}
\hline Variable & Value & Units \\
\hline Area of collector, $A_{c_{\_} E T}\left(\right.$ adjusted $\left.^{*}\right)$ & 1 & $\mathrm{~m}^{2}$ \\
\hline Solar irradiance, $S_{-E T}$ & 800 & $\mathrm{~W} / \mathrm{m}^{2}$ \\
\hline Receiver emissivity, $\varepsilon_{\mathrm{r}_{-} \mathrm{ET}}$ & 0.93 & \\
\hline Outside diameter of receiver, $\mathrm{D}_{\text {ro_ET }}$ & 0.047 & $\mathrm{~m}$ \\
\hline Thickness of receiver tube, $\mathrm{t}_{\mathrm{E}}$ (assumed) & 0.0018 & $\mathrm{~m}$ \\
\hline Inside diameter of receiver, $\mathrm{D}_{\text {ri_ET }}$ & 0.0434 & $\mathrm{~m}$ \\
\hline Length of receiver, $\mathrm{L}_{\mathrm{r} \_ \text {ET }}$ (adjusted*) & 1 & $\mathrm{~m}$ \\
\hline Thermal conductivity of receiver, $\mathrm{k}_{\mathrm{r}_{-} \mathrm{ET}}$ & 401 & $\mathrm{~W} / \mathrm{mK}$ \\
\hline Receiver area, $\mathrm{A}_{\mathrm{r}_{-} \mathrm{ET}}\left(\right.$ adjusted $\left.^{*}\right)$ & 0.638242 & $\mathrm{~m}^{2}$ \\
\hline Aperture area, $\mathrm{A}_{\mathrm{a} \_\mathrm{ET}}\left(\right.$ adjusted $\left.^{*}\right)$ & 0.727273 & $\mathrm{~m}^{2}$ \\
\hline Outside diameter of cover, $\mathrm{D}_{\text {co_ET }}$ & 0.058 & $\mathrm{~m}$ \\
\hline Thickness of glass cover, $\mathrm{t}_{\mathrm{g} \_\mathrm{ET}}$ & 0.0018 & $\mathrm{~m}$ \\
\hline Inside diameter of cover, $\mathrm{D}_{\text {ci_ET }}$ & 0.0544 & $\mathrm{~m}$ \\
\hline Glass emissivity, $\varepsilon_{\mathrm{g}_{\_} \mathrm{ET}}$ & 0.8 & \\
\hline Thermal conductivity of cover, $\mathrm{k}_{\mathrm{g}_{\_} \mathrm{ET}}$ & 1.2 & $\mathrm{~W} / \mathrm{mK}$ \\
\hline Working fluid flow rate, $\mathrm{mfr}_{\mathrm{ET}}$ & 0.0078 & $\mathrm{~kg} / \mathrm{s}$ \\
\hline Heat transfer coefficient inside tube, $\mathrm{h}_{\mathrm{f}_{-} \text {ET }}$ & 300 & $\mathrm{~W} / \mathrm{m}^{2} \mathrm{~K}$ \\
\hline Specific heat capacity of working fluid, $\mathrm{C}_{\mathrm{p}_{-} \mathrm{ET}}$ & 3600 & $\mathrm{~J} / \mathrm{kgK}$ \\
\hline Ambient air temperature, $\mathrm{T}_{\mathrm{a} \_\mathrm{ET}}$ & 293 & $\mathrm{~K}$ \\
\hline Sky temperature, $\mathrm{T}_{\mathrm{S}_{-} \mathrm{ET}}$ & 287 & $\mathrm{~K}$ \\
\hline
\end{tabular}

*Note that the actual area of the panel is $3 \mathrm{~m}^{2}$; this area and corresponding geometry was scaled to a $1 \mathrm{~m}^{2}$ basis for ease of calculation. 


\section{Appendix B: IDF Text}

\section{ERV}

HeatExchanger:AirToAir:SensibleAndLatent,

OA Heat Recovery 1, !- Name

HVACOperationSchd, !- Availability Schedule Name

0.4333, !- Nominal Supply Air Flow Rate $\{\mathrm{m} 3 / \mathrm{s}\}$

0.76, !- Sensible Effectiveness at 100\% Heating Air Flow \{dimensionless \}

0.68, !- Latent Effectiveness at 100\% Heating Air Flow \{dimensionless \}

0.81, !- Sensible Effectiveness at 75\% Heating Air Flow \{dimensionless\}

0.73, !- Latent Effectiveness at 75\% Heating Air Flow \{dimensionless

0.76, !- Sensible Effectiveness at 100\% Cooling Air Flow \{dimensionless

0.68, !- Latent Effectiveness at 100\% Cooling Air Flow \{dimensionless

0.81, !- Sensible Effectiveness at 75\% Cooling Air Flow \{dimensionless \}

0.73, !- Latent Effectiveness at 75\% Cooling Air Flow \{dimensionless \}

Outside Air Inlet Node Preheated, !- Supply Air Inlet Node Name

Heat Recovery Outlet Node, !- Supply Air Outlet Node Name

Relief Air Outlet Node, !- Exhaust Air Inlet Node Name

Heat Recovery Secondary Outlet Node, !- Exhaust Air Outlet Node Name

200.0, !- Nominal Electric Power $\{\mathrm{W}\}$

No, !- Supply Air Outlet Temperature Control

Rotary, !- Heat Exchanger Type

None; !- Frost Control Type

\section{Version 7.2 - 9.0 Translation Adjustments}

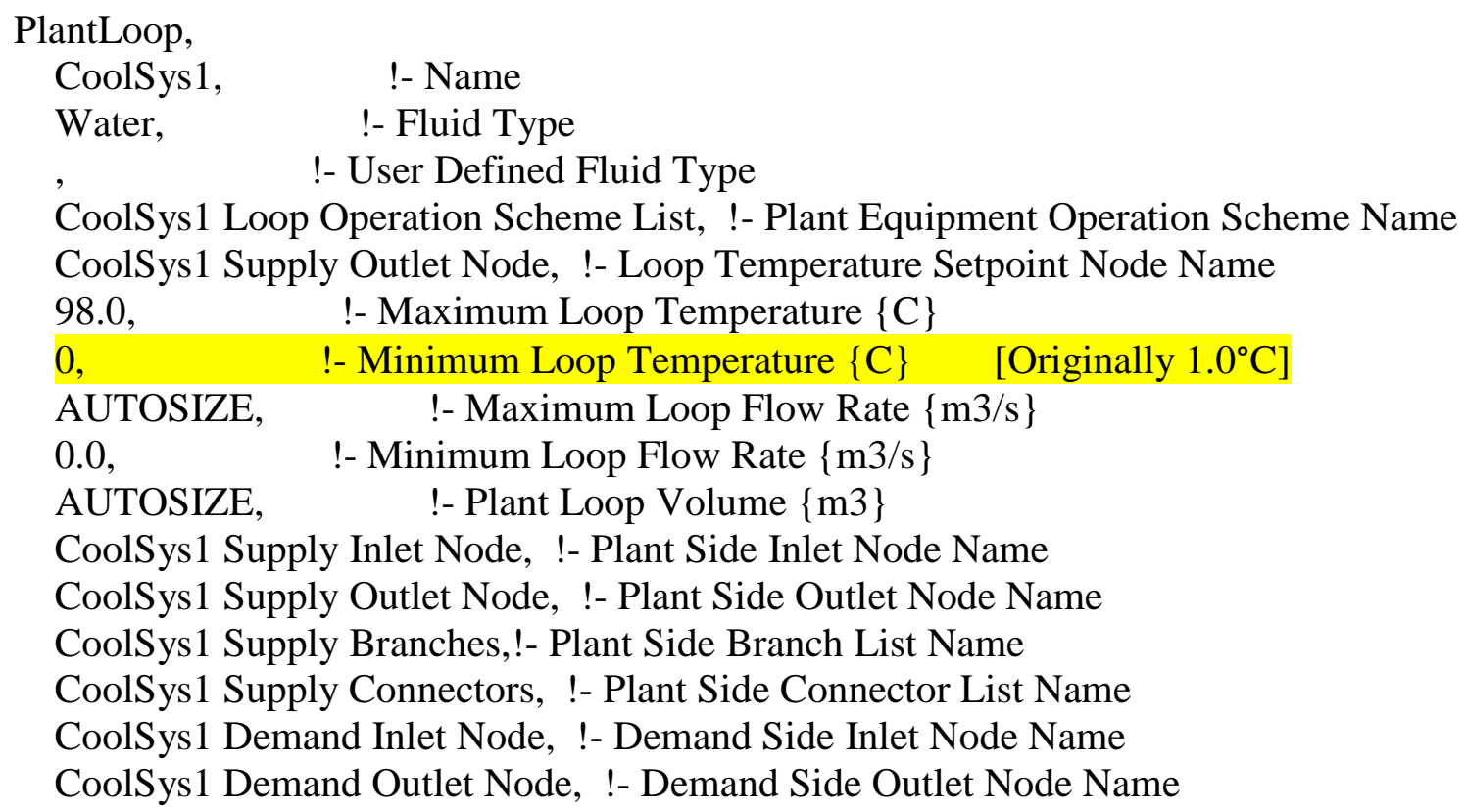


CoolSys1 Demand Branches,!- Demand Side Branch List Name

CoolSys1 Demand Connectors, !- Demand Side Connector List Name

UniformLoad; !- Load Distribution Scheme

PlantLoop,

HeatSys 1, !- Name

Water, !- Fluid Type

!- User Defined Fluid Type

HeatSys1 Loop Operation Scheme List, !- Plant Equipment Operation Scheme Name HeatSys 1 Supply Outlet Node, !- Loop Temperature Setpoint Node Name

100.0, !- Maximum Loop Temperature $\{\mathrm{C}\}$

0 ,

!- Minimum Loop Temperature $\{\mathrm{C}\}$ [Originally $\left.10.0^{\circ} \mathrm{C}\right]$

AUTOSIZE, !- Maximum Loop Flow Rate $\{\mathrm{m} 3 / \mathrm{s}\}$

0.0, !- Minimum Loop Flow Rate $\{\mathrm{m} 3 / \mathrm{s}\}$

AUTOSIZE, !- Plant Loop Volume $\{\mathrm{m} 3\}$

HeatSys1 Supply Inlet Node, !- Plant Side Inlet Node Name

HeatSys 1 Supply Outlet Node, !- Plant Side Outlet Node Name

HeatSys 1 Supply Branches,!- Plant Side Branch List Name

HeatSys1 Supply Connectors, !- Plant Side Connector List Name

HeatSys1 Demand Inlet Node, !- Demand Side Inlet Node Name

HeatSys1 Demand Outlet Node, !- Demand Side Outlet Node Name

HeatSys1 Demand Branches,!- Demand Side Branch List Name

HeatSys1 Demand Connectors, !- Demand Side Connector List Name

Optimal; !- Load Distribution Scheme

PlantLoop,

SWHSys 1, !- Name

Water, !- Fluid Type

!- User Defined Fluid Type

SWHSys 1 Loop Operation Scheme List, !- Plant Equipment Operation Scheme Name

SWHSys1 Supply Outlet Node, !- Loop Temperature Setpoint Node Name

60.0, !- Maximum Loop Temperature $\{\mathrm{C}\}$

$0, \quad$ !- Minimum Loop Temperature $\{\mathrm{C}\}$ [Originally $10.0^{\circ} \mathrm{C}$ ]

AUTOSIZE, !- Maximum Loop Flow Rate $\{\mathrm{m} 3 / \mathrm{s}\}$

0.0, !- Minimum Loop Flow Rate $\{\mathrm{m} 3 / \mathrm{s}\}$

AUTOSIZE, !- Plant Loop Volume $\{\mathrm{m} 3\}$

SWHSys 1 Supply Inlet Node, !- Plant Side Inlet Node Name

SWHSys 1 Supply Outlet Node, !- Plant Side Outlet Node Name

SWHSys1 Supply Branches, !- Plant Side Branch List Name

SWHSys 1 Supply Connectors, !- Plant Side Connector List Name

SWHSys1 Demand Inlet Node, !- Demand Side Inlet Node Name

SWHSys1 Demand Outlet Node, !- Demand Side Outlet Node Name

SWHSys1 Demand Branches, !- Demand Side Branch List Name

SWHSys1 Demand Connectors, !- Demand Side Connector List Name

Optimal; !- Load Distribution Scheme 
CondenserLoop,

TowerWaterSys, !- Name

Water, !- Fluid Type

!- User Defined Fluid Type

TowerWaterSys Loop Operation Scheme List,!- Condenser Equipment Operation Scheme Name

TowerWaterSys Supply Outlet Node, !- Condenser Loop Temperature Setpoint Node Name 80.0, !- Maximum Loop Temperature $\{\mathrm{C}\}$

$0, \quad$ !- Minimum Loop Temperature $\{\mathrm{C}\}$ [Originally $5.0^{\circ} \mathrm{C}$ ]

AUTOSIZE, $\quad$ !- Maximum Loop Flow Rate $\{\mathrm{m} 3 / \mathrm{s}\}$

0.0 , !- Minimum Loop Flow Rate $\{\mathrm{m} 3 / \mathrm{s}\}$

AUTOSIZE, !- Condenser Loop Volume $\{\mathrm{m} 3\}$

TowerWaterSys Supply Inlet Node, !- Condenser Side Inlet Node Name

TowerWaterSys Supply Outlet Node, !- Condenser Side Outlet Node Name

TowerWaterSys Supply Branches, !- Condenser Side Branch List Name

TowerWaterSys Supply Connectors, !- Condenser Side Connector List Name

TowerWaterSys Demand Inlet Node, !- Demand Side Inlet Node Name

TowerWaterSys Demand Outlet Node, !- Demand Side Outlet Node Name

TowerWaterSys Demand Branches, !- Condenser Demand Side Branch List Name

TowerWaterSys Demand Connectors, !- Condenser Demand Side Connector List Name

SequentialLoad; !- Load Distribution Scheme 
